\title{
A Detailed Kinetico-Mechanistic Investigation on the Palladium C-H Bond Activation in Azobenzenes and their Monopalladated Deriva- tives
}

\author{
Alen Bjelopetrović, ${ }^{\text {ał }}$ Dajana Barišić, ${ }^{\text {ał }}$ Zrinka Duvnjak, ${ }^{\mathrm{b}}$ Ivan Džajić, ${ }^{\mathrm{b}}$ Marina Juribašić Kulcsár, ${ }^{\mathrm{a}}$ Ivan \\ Halasz, ${ }^{a}$ Manuel Martínez, ${ }^{\mathrm{c}, \mathrm{d}^{*}}$ Ana Budimir, ${ }^{\mathrm{b} *}$ Darko Babić, ${ }^{\mathrm{a}^{*}}$ and Manda Ćurić, ${ }^{\mathrm{a}^{*}}$

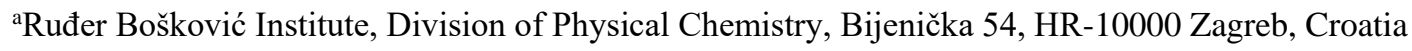 \\ ${ }^{b}$ University of Zagreb, Faculty of Pharmacy and Biochemistry, Ante Kovačića 1, 10000 Zagreb, Croatia \\ 'Departament de Química Inorgànica i Orgànica, Secció de Química Inorgànica, Martí i Franquès 1-11, E-08028 Barcelona, \\ Spain \\ ${ }^{\mathrm{d}}$ Institute of Nanoscience and Nanotechnology (IN2UB), Universitat de Barcelona, Barcelona, Spain \\ Supporting Information Placeholder
}

\begin{abstract}
Palladium C-H bond activation in azobenzenes with $\mathrm{R}_{1}$ and $\mathrm{R}_{2}$ at para-positions of the phenyl rings $\left(\mathrm{R}_{1}=\mathrm{NMe}_{2}, \mathrm{R}_{2}=\mathrm{H}\right.$ (L1); $\mathrm{R}_{1}=\mathrm{NMe}_{2}, \mathrm{R}_{2}=\mathrm{Cl}(\mathbf{L 2}) ; \mathrm{R}_{1}=\mathrm{NMe}_{2}, \mathrm{R}_{2}=\mathrm{I}(\mathbf{L 3}) ; \mathrm{R}_{1}=\mathrm{NMe}_{2}, \mathrm{R}_{2}=\mathrm{NO}_{2}(\mathbf{L} 4) ; \mathrm{R}_{1}=\mathrm{H}, \mathrm{R}_{2}=\mathrm{H}(\mathbf{L 5})$ ) and their monopalladated derivatives, using $c i s$ - $\left[\mathrm{PdCl}_{2}(\mathrm{DMF})_{2}\right]$, has been studied in detail by in situ ${ }^{1} \mathrm{H}$ NMR spectroscopy in $N, N$-dimethylformamide- $d_{7}$ (DMF- $d_{7}$ ) at room temperature; the same processes have been monitored in parallel via time-resolved UV-Vis spectroscopy in DMF at different temperatures and pressures. The final goal was to achieve, from a kinetico-mechanistic perspective, a complete insight on previously reported reactivity results. The results suggest the operation of an electrophilic concerted metallation and deprotonation mechanism for both the mono- and dipalladation reactions, occurring from the coordination compound and the monopalladated intermediates, respectively. The process involves deprotonation of the $\mathrm{C}-\mathrm{H}$ bond assisted by the presence of a coordinated DMF molecule, that acts as a base. For the first time, NMR monitoring provides a direct evidence of all the intermediate stages, that is: $i$ ) coordination of the azo ligand to $\mathrm{Pd}^{\mathrm{II}}$ center, ii) formation of the monopalladated species, iii) coordination of the monopalladated species to another $\mathrm{Pd}^{\mathrm{II}}$ unit, which finally result in the $i v$ ) formation of the dipalladated product. All of these species have been identified as intermediates in the dipalladation of azobenzenes, evidenced also by UV-Vis spectroscopy time-resolved monitoring. The data also confirms that the cyclopalladation of asymmetrically substituted azobenzenes occurs by two concurrent reaction paths. In order to identify the species observed by NMR and by UV-Vis spectroscopies, the final products, intermediates and the $\mathrm{Pd}^{\mathrm{II}}$ precursor have been prepared and characterized by X-ray diffraction, IR and NMR spectroscopies. DFT calculations have also been used in order to explain the isomerism observed for the isolated complexes, as well to assign their NMR and IR spectra.
\end{abstract}

\section{INTRODUCTION}

Cyclopalladation continuously attracts considerable interest, not only as the most direct route for the synthesis of palladacycles, ${ }^{1}$ but also as a generally important reaction in organic synthetic chemistry. ${ }^{2}$ Palladacycles are identified as crucial intermediates in many organic reactions promoted by palladium precursors, that result in functionalized hydrocarbons. ${ }^{1,2}$ Therefore, a detailed understanding of cyclopalladation pathways of different organic substrates is essential. Cyclopalladation is recognized as a two-step reaction involving the coordination of palladium center by a directing group, which leads to selective intramolecular activation of the $\mathrm{C}-$ $\mathrm{H}$ bond, resulting in the formation of the $\mathrm{Pd}-\mathrm{C}$ bond with simultaneous proton release and ring closure. ${ }^{1 \mathrm{c}, 3}$ This mechanism is supported by our kinetico-mechanistic studies on a variety of compounds, ${ }^{4}$ and specifically by our previous studies of the mono- and dicyclopalladation of azobenzene and its 4,4'-functionalized derivatives using trans-[ $\mathrm{PdCl}_{2}\left(\mathrm{MeCN}_{2}\right]$ as the precursor. ${ }^{4 \mathrm{~b}}$

The kinetics of the latter processes had been studied by UV-Vis time-resolved spectroscopy in $N, N$-dimethylformamide (DMF) at room temperature, as this is the solvent for numerous $\mathrm{Pd}^{\mathrm{II}}$-catalyzed reactions. ${ }^{2 \mathrm{f}, 5}$ Rationalization of the experimental kinetic data by DFT calculations had provided a convincing mechanistic picture of the electrophilic attack at the phenyl ring within the Pd-azobenzene complex. ${ }^{4 a, b}$

To provide a complete understanding of that work, here we present a kinetico-mechanistic study of the cyclopalladation of azobenzenes and their monopalladated compounds (Chart 1) both by NMR and UV-Vis spectroscopies. The time-resolved ${ }^{1} \mathrm{H}$ NMR study has allowed, for the first time, a full and detailed insight into the nature and reactivity of the intermediates formed during these reactions. The $\mathrm{Pd}^{\mathrm{II}}$ precursor, $c i s-\left[\mathrm{PdCl}_{2}(\mathrm{DMF})_{2}\right]$, and most of the detected intermediates have been isolated and characterized both structurally and spectroscopically. These results provided direct evidence that dipalladation of azobenzenes proceeds via two parallel 
pathways when asymmetrically substituted azobenzenes are used, and that each of them consists of four consecutive steps. Furthermore, the UV-Vis spectroscopy at different temperatures and pressures has allowed for the first time the obtention of detailed kineticomechanistic information by determining activation parameters, both thermal $\left(\Delta H^{\ddagger}, \Delta S^{\ddagger}\right)$ and pressure $\left(\Delta V^{\ddagger}\right)$.

Chart 1. Molecular structure of the azobenzene and its coordination, mono- and dicyclopalladated derivatives, used in this study. Only $\alpha$-isomers of An, Mn and MAn are shown.

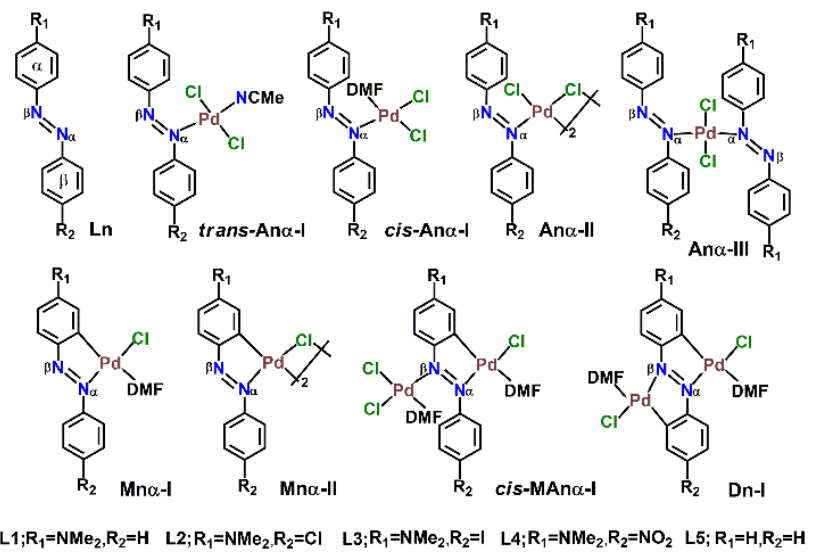

\section{RESULTS AND DISCUSSION}

Compounds. The $\mathrm{Pd}^{\mathrm{II}}$ precursor, coordination, mono- and dipalladated complexes of the azobenzenes studied (Chart 1) have been isolated and structurally characterized by X-ray diffraction and IR spectroscopy in the solid-state, and by NMR spectroscopy in solution.

Pd ${ }^{\mathrm{II}}$ precursor. cis- $\left[\mathrm{PdCl}_{2}(\mathrm{DMF})_{2}\right]$ was obtained in high yield by aging $\mathrm{PdCl}_{2}$ in a vapor of $N, N-$ dimethylformamide $(\mathrm{DMF}){ }^{6}$ and also by evaporation and cooling of a DMF solution of $\mathrm{PdCl}_{2}$. Its molecular structure, resolved by powder X-ray diffraction (PXRD), indicates a cis-configuration at the $\mathrm{Pd}^{\mathrm{II}}$ center and the coordination of the oxygen donors from the two DMF ligands (Figure 1). The IR spectrum of the isolated product provided additional support for the cis configuration, as two bands are observed for both $\mathrm{Pd}-\mathrm{Cl}$ and $\mathrm{Pd}-\mathrm{O}$ stretching vibrations (Figure $\mathrm{S} 2$ ).

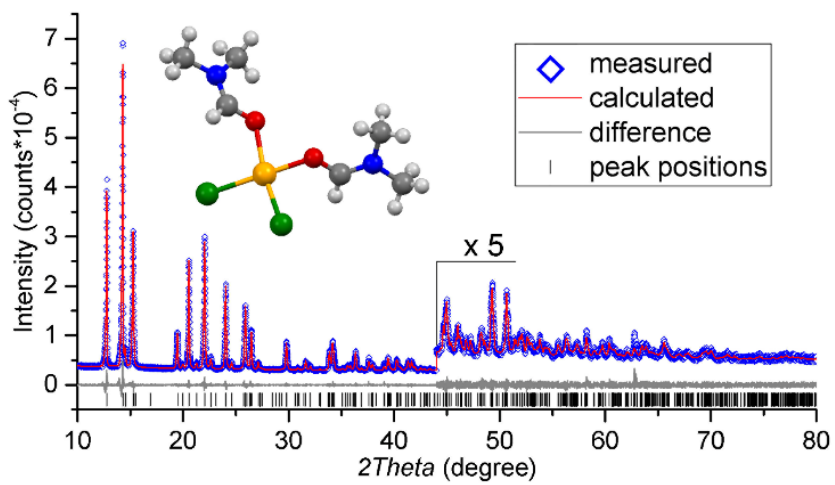

Figure 1. Powder X-ray diffraction of the calculated molecular structure of $c i s-\left[\mathrm{PdCl}_{2}(\mathrm{DMF})_{2}\right]$ and its final Rietveld refinement.

Despite existing reports on the isolation and characterization of the trans-isomer, ${ }^{7}$ all our attempts to obtain trans-[PdCl${ }_{2}\left(\mathrm{DMF}_{2}\right]$ from DMF solutions were unsuccessful. Cooling down of the concentrated DMF solution of $c i s-\left[\mathrm{PdCl}_{2}\left(\mathrm{DMF}_{2}\right]\right.$ to $-25^{\circ} \mathrm{C}$ resulted in quantitative precipitation only of the cis-isomer as confirmed by PXRD and IR spectra (Figures S1 and S2). DFT calculations support this finding, although only by a $1 \mathrm{kcal} / \mathrm{mol}$ free energy difference in favor of the $c i s$-[ $\mathrm{PdCl}_{2}\left(\mathrm{DMF}_{2}\right]$ isomer. ${ }^{4 \mathrm{~b}}$

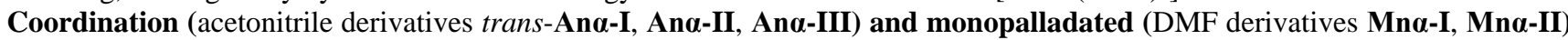
compounds. The coordination and monopalladated complexes were prepared in MeCN and DMF solution, respectively, by the procedure already developed for $\mathbf{A} \mathbf{2} \boldsymbol{\alpha}-\mathbf{I}$ and $\mathbf{M} \mathbf{2} \boldsymbol{\alpha}-\mathbf{I}^{8}{ }^{8}$

The reactions of $\mathbf{L 1}$ and $\mathbf{L 3}$ with $\mathrm{PdCl}_{2}$ in a 1:1 molar ratio afforded the respective acetonitrile derivatives of trans-A1 $\alpha-\mathbf{I}$ and trans-A3 $\boldsymbol{\alpha}$-I complexes, as confirmed by X-ray single-crystal diffraction analysis (Figures 3, S5 and S6) and NMR spectroscopy. Despite the fact that two isomers, $\alpha$ and $\beta$, can be formed in the reactions of $\mathrm{PdCl}_{2}$ with the unsymmetrically substituted azobenzenes, ${ }^{9}$ all the coordination compounds obtained show the palladium center bound to the $\mathrm{N}_{\alpha}$ of azobenzene. Chart 1 shows the cis-An $\alpha-\mathrm{I}$ complexes with $\mathrm{DMF}$, as they are the primary product of the reaction with cis- $\left[\mathrm{PdCl}_{2}(\mathrm{DMF})_{2}\right]$, and also the productive isomers in cyclopalladation; ${ }^{4 a}$ for this reason from now on in this work they weiil be reffered simply as An $\alpha$-I. 
For A1 $\alpha, \mathbf{A} 2 \alpha$ and $\mathbf{A 3 \alpha}$ structures only monomeric species have been isolated, but for $\mathbf{A 4} \boldsymbol{\alpha}$ a mixture of monomeric and dimeric

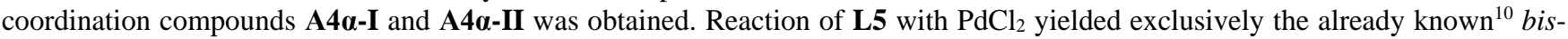
complex A5-III, regardless of the $\mathbf{L 5}$ to Pd molar ratio used. The product was structurally identified by comparison of its powder diffraction (PXRD) pattern with that simulated from its known single crystal structure (Figure S3). ${ }^{10}$

Stirring in DMF solution the coordination complexes indicated above produces the monopalladated monomeric M1 $\alpha$-I and M3 $\alpha-$ I, or dimeric M4a-II compounds. The analogous reaction with A5-III resulted in a mixture of free azobenzene ligand, monopalladated and dipalladated species. Neat M5-II, was only obtained by the reaction of $\mathbf{L 5}$ with $\mathrm{Na}_{2}\left[\mathrm{PdCl}_{4}\right]$ in methanol, as already described. ${ }^{11}$ The ${ }^{1} \mathrm{H}$ NMR spectral data, along with the elemental analysis (see Experimental), support the formulation of the isolated monopalladated products as monomeric $[\mathrm{PdCl}(\mathbf{L n}-\mathrm{H})(\mathrm{DMF})](\mathbf{M} \mathbf{\alpha}-\mathbf{I}$ and $\mathbf{M 3} \boldsymbol{\alpha}-\mathbf{I})$ and dimeric $[\mathrm{Pd}(\mu-\mathrm{Cl})(\mathbf{L n}-\mathrm{H})]_{2}(\mathbf{M} 4 \boldsymbol{\alpha}-\mathbf{I I}$ and $\mathbf{M 5}-$ II) species. The molecular structure of the new monomeric M1 $\alpha$-I product, resolved by X-ray single-crystal diffraction, confirmed the formation of the isomer with the palladium center bonded to the $\mathrm{N}_{\alpha}$ donor and to the phenyl ring bearing the electron-donating $\mathrm{NMe}_{2}$ group (Figures 2, S7 and Table S1). The formation of the dimeric monopalladated azobenzene M5-II was confirmed by its powder diffraction (PXRD) pattern, which is in good agreement with that simulated from the already known single crystal structure ${ }^{12}$ (Figure S4). ${ }^{1} \mathrm{H}$ NMR spectra of the dimeric M4 $\alpha$-II and M5-II compounds indicate that these convert into the monomeric M4a-I and M5-I species in DMF solution, with the shift pattern of their signals being equivalent to those of the M1 $\alpha-\mathbf{I}-\mathbf{M 3} \boldsymbol{\alpha}-\mathbf{I}$ compounds.

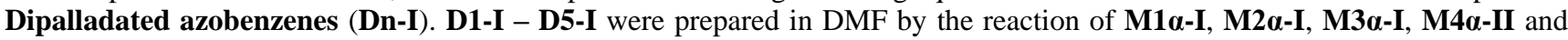
M5-II with cis- $\left[\mathrm{PdCl}_{2}(\mathrm{DMF})_{2}\right]$, which is a new procedure diverse from previous preparations that started directly from the azoderivatives $\mathbf{L 1}$ - L5. $^{4 \mathrm{~b}}$

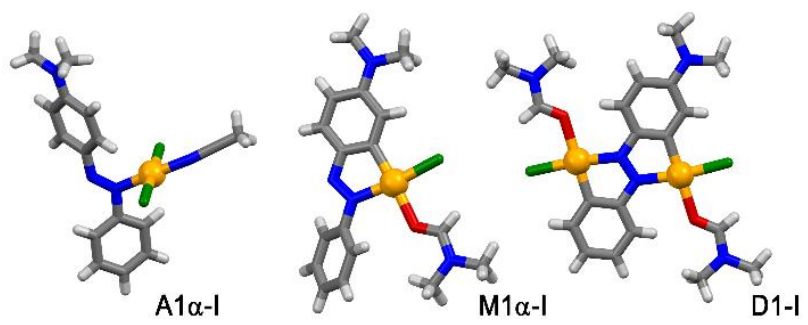

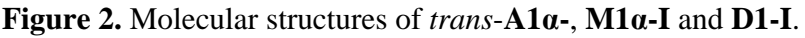

The products were structurally identified by comparison with the PXRD, IR and NMR spectra of the already known compounds. Additionally, single crystals were obtained and analyzed for D1-I (Figures 2, S8 and Table S1); bond distances and angles around the palladium coordination sphere are similar to those found and calculated for other dipalladated azobenzenes. ${ }^{4 \mathrm{~b}, 13}$

DFT calculations on the speciation of the compounds studied. The different forms of the isolated coordination and monopalladated complexes prompted us to examine whether this isomerism can be attributed to diverse isomer stabilities. The equilibrium

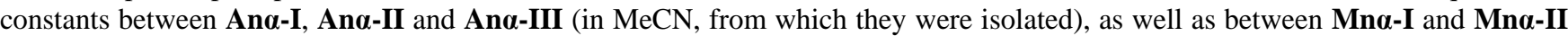
(in DMF, the solvent used in their preparation), were evaluated from the quantum-chemical free energies of the corresponding molecular species. The calculated equilibrium compositions involved only Ano-I and Ano-III species, with negligible concentrations of Ano-II complexes. A1 $\alpha$-I and A5-III were predicted as major forms in agreement with experimental findings. The calculations indicated A2 $\boldsymbol{A}$-III and A3 $\mathbf{A}$-III as dominant isomeric species, in contrast to the fact that only $\mathbf{A 2} \boldsymbol{\alpha}$-I and A3 $\alpha-\mathbf{I}$ have been isolated. Similarly, A4 $\boldsymbol{\alpha}$-III was predicted as dominant, in opposition to the experimentally obtained mixture of A4a-I and A4a-II. All monopalladated monomeric species, Mna-I, were predicted as dominant, contrary to the experimentally observed M4a-II. The disagreements can be assigned to the unaccounted solvent interactions or crystal packing effects (different solubilities). But it is also possible that the presently available computational methods are not sufficiently precise to predict fine differences in the isomer stabilities. Agreement with the experimental findings can be established by shifting of the computational results within $1 \mathrm{kcal} / \mathrm{mol}$, which is commonly considered as a computational error margin.

Kinetico-mechanistic studies. Our previous UV-Vis time-resolved monitoring of the reactions at $25^{\circ} \mathrm{C}$ and atmospheric pressure had indicated that the dipalladation of the azobenzenes used in this study is a multistep process. The full reactivity involves the formation of the intermediates Ano-I and MAno-I (see Chart 1) in fast pre-equilibria, prior to the rate-determining steps generating mono- and dipalladated species Mno-I and Dn-I, respectively, (Scheme 1 and equations (1) and (2)). ${ }^{4 \mathrm{~b}}$

UV-Vis time-resolved monitoring. Since the full set of activation parameters, $\Delta H^{\ddagger}, \Delta S^{\ddagger}$ and $\Delta V^{\ddagger}$, provide determinant information on the cyclopalladation mechanism, ${ }^{4 \mathrm{e}, 15}$ the reactions of $\mathbf{L 1 - L 4}$ and $\mathbf{M 1} \boldsymbol{\alpha}-\mathbf{I}-\mathbf{M} \mathbf{4} \boldsymbol{\alpha}$-I, with cis- $\left[\mathrm{PdCl}_{2}(\mathrm{DMF})_{2}\right]$ in DMF were monitored by UV-Vis time-resolved spectroscopy at varying temperatures and pressures.

Scheme 1. Full dipalladation process of the azobenzenes studied. ${ }^{4 b}\{\mathrm{Pd}\}$ represents $c i s-\left[\operatorname{PdCl}_{2}\left(\mathrm{DMF}_{2}\right]\right.$.

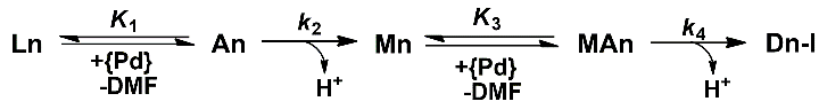




$$
\begin{aligned}
& k_{o b s(1)}=\frac{k_{2} K_{1}[\mathrm{Pd}]}{1+K_{1}[\mathrm{Pd}]} \\
& k_{o b s(2)}=\frac{k_{4} K_{3}[\mathrm{Pd}]}{1+K_{3}[\mathrm{Pd}]}
\end{aligned}
$$

All reactions were carried out under pseudo-first order conditions, with a large molar excess of $c i s$ - $\left[\mathrm{PdCl}_{2}(\mathrm{DMF})_{2}\right]$. Monitoring of the reactions of $\mathbf{L 1}-\mathbf{L} 4$ with cis-[ $\left.\mathrm{PdCl}_{2}(\mathrm{DMF})_{2}\right]$ indicated the presence of a two-step sequence in the full palladation process, as observed before. ${ }^{4 b}$
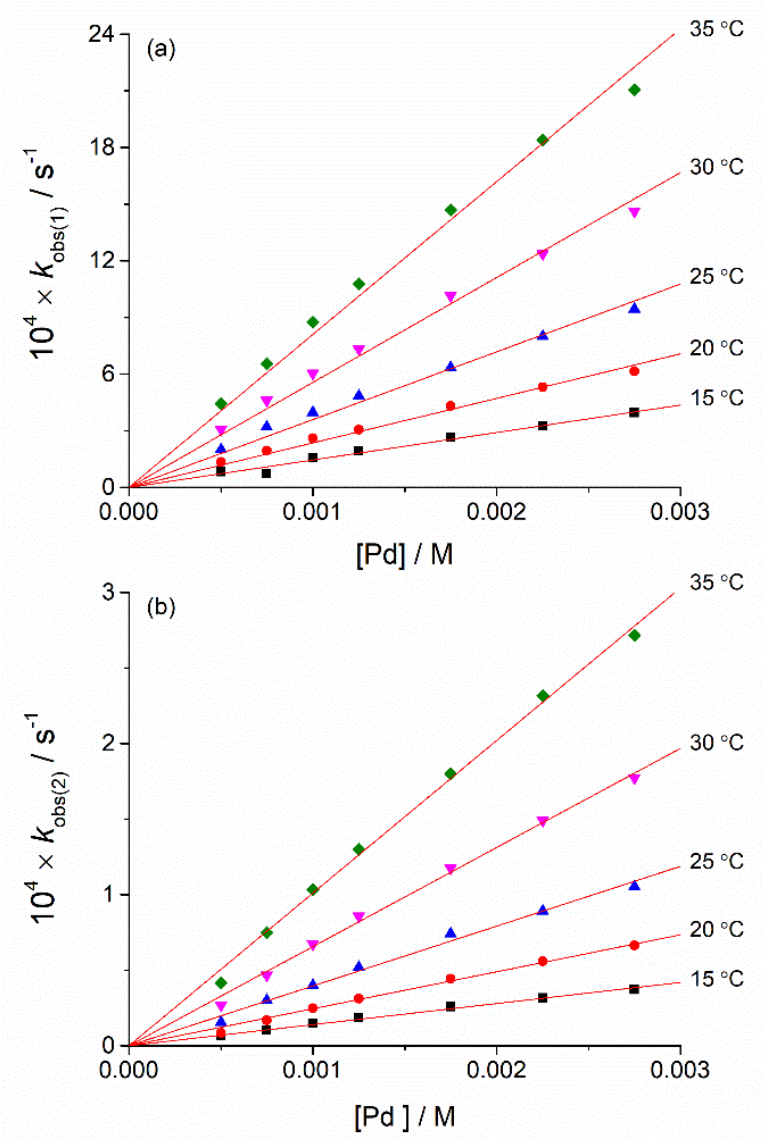

Figure 3. Dependence of the pseudo-first-order rate constants for the first, $k_{\mathrm{obs}(1)}$, (a) and second, $k_{\mathrm{obs}(2)}$, (b) cyclopalladation of $\mathbf{L} \mathbf{2}$ on [Pd] in DMF at different temperatures; $[\mathbf{L 2}]=25 \mu \mathrm{M}$.

The observed pseudo-first order constants $k_{\mathrm{obs}(1)}$ and $k_{\mathrm{obs}(2)}$ were calculated from the time-resolved spectral changes using a consecutive $\mathrm{A} \rightarrow \mathrm{B} \rightarrow \mathrm{C}$ model. The dependence of $k_{\mathrm{obs}(1)}$ and $k_{\mathrm{obs}(2)}$ on the $c i s$-[ $\left.\mathrm{PdCl}_{2}(\mathrm{DMF})_{2}\right]$ concentration (in excess, Figure 3), lead us to consider as valid the reaction mechanism and the rate law depicted by Scheme 1 and equations (1) and (2) for the systems studied. The lack of curvature in the plots of Figure 3 indicate that $K_{1}$ and $K_{3}$ have sufficiently low values to avoid a saturation behaviour. ${ }^{15}$ The values of the $k_{2} K_{1}$ and $k_{4} K_{3}$ products for the reactions of the L1-L4 ligands, determined from the slopes of the $k_{\mathrm{obs}(1)}$ and $k_{\mathrm{obs}(2)}$ versus [Pd] data at variable temperature and pressure (Table S2, Figures 3 and S9), agree with former experiments at room temperature. ${ }^{4 b}$ 


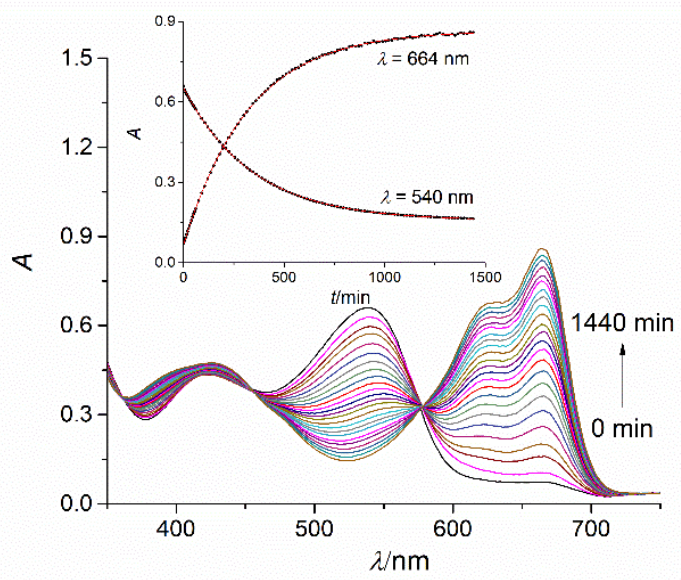

Figure 4. UV-Vis time-resolved spectral changes for the reaction $c i s-\left[\mathrm{PdCl}_{2}(\mathrm{DMF})_{2}\right]+\mathbf{M} 2 \boldsymbol{\alpha}-\mathbf{I} \rightarrow \mathbf{D} 2-\mathbf{I}$, in $\mathrm{DMF}$. $[\mathbf{M} 2 \boldsymbol{\alpha}]=25 \mu \mathrm{M},[\mathrm{Pd}]=$ $1.0 \mathrm{mM}, T=25^{\circ} \mathrm{C}$. The inset shows the kinetic traces at 540 and $664 \mathrm{~nm}$, along with their fitting to an A $\rightarrow$ B process.

As shown in Figure 4, the time-resolved spectral changes recorded during the reaction of $c i s-\left[\mathrm{PdCl}_{2}(\mathrm{DMF})_{2}\right]$ with $\mathbf{M 1} \boldsymbol{\alpha}-\mathbf{I}-\mathbf{M} 4 \boldsymbol{\alpha}-$ I can be fitted to the simple $\mathrm{A} \rightarrow \mathrm{B}$ model. The pseudo-first-order rate constants $k_{\mathrm{obs}}$ derived show a linear dependence on the palladium concentration (Figure $\mathrm{S} 10$ ), and produce a set of second order rate constants, $k_{4} K_{3}$, (Table $\mathrm{S} 2$ ), that are expected to be equivalent to that obtained for the second part of the mechanism in Scheme 1, i.e., the second cyclopalladation of $\mathbf{L n}^{4 \mathrm{~b}}$

The fitting of the variation of $k_{2} K_{1}$ and $k_{4} K_{3}$ for the reactions of $\mathbf{L n}$, or $k_{4} K_{3}$ for those of $\mathbf{M n} \boldsymbol{\alpha}-\mathbf{I}$, at different temperatures, using the standard Eyring plots (Figures 5a and S11), produce the values of the thermal activation parameters $\left(\Delta H^{\ddagger}\right.$ and $\left.\Delta S^{\ddagger}\right)$ indicated in Table 1.

The pressure activation parameters $\left(\Delta V^{*}\right)$, determined by the variation of the second order rate constants for the reaction of $\mathbf{L n}$ (calculated as $k_{\mathrm{obs}} /[\mathrm{Pd}]$, see Experimental) at different pressures, using the standard $\ln (k)$ versus $P$ equation (Figures $5 \mathrm{~b}$ and $\mathrm{S} 12$ ), are also summarized in Table 1. The pressure variation of the values of $k_{4} K_{3}$ for the reaction to Dn-I from the Mno-I intermediates instead of the Ln, was also conducted at varying pressures. As seen in Figures 5b and S12 and Table 1, the values determined are in very close agreement with those obtained for the second step observed on the reaction of the precursor with of Ln. Consequently, $\Delta V_{2}^{\ddagger}$ was considered independent of the origin of the monometallated intermediate within the error involved in its determination

Table 1. Summary of the kinetic $(298 \mathrm{~K})$ and thermal and pressure activation parameters determined for the cyclopalladation reaction of azobenzenes L1-L4 and their monopalladated derivatives M1 $\alpha-I$ - M4 $\alpha-I$ in DMF solution.

\begin{tabular}{|c|c|c|c|c|c|c|c|c|}
\hline Compound & $\begin{array}{l}298 k_{2} K_{1} \\
\mathrm{M}^{-1} \mathrm{~s}^{-1} \\
\end{array}$ & $\begin{array}{c}\Delta H_{1}^{\ddagger} \\
\mathrm{kJ} \mathrm{mol}^{-1}\end{array}$ & $\begin{array}{c}\Delta S_{1^{\ddagger}} \\
\mathrm{JK}^{-1} \mathrm{~mol}^{-1} \\
\end{array}$ & $\begin{array}{c}\Delta V_{1^{\ddagger}} \\
\mathrm{cm}^{3} \mathrm{~mol}^{-1} \\
\end{array}$ & $\begin{array}{l}298 k_{4} K_{3} \\
\mathrm{M}^{-1} \mathrm{~s}^{-1} \\
\end{array}$ & $\begin{array}{c}\Delta H_{2}^{\ddagger} \\
\mathrm{kJ} \mathrm{mol}^{-1}\end{array}$ & $\begin{array}{c}\Delta S_{2^{\ddagger}} \\
\mathrm{J} \mathrm{K}^{-1} \mathrm{~mol}^{-1} \\
\end{array}$ & $\begin{array}{c}\Delta V_{2}^{\ddagger} \\
\mathrm{cm}^{3} \mathrm{~mol}^{-1} \\
\end{array}$ \\
\hline L1 & 0.44 & $64 \pm 2$ & $-37 \pm 6$ & $-12 \pm 1$ & 0.060 & $60 \pm 3$ & $-67 \pm 8$ & $-15 \pm 2$ \\
\hline M1 $\alpha-I$ & - & - & - & - & 0.071 & $59 \pm 1$ & $-71 \pm 2$ & $-11 \pm 2$ \\
\hline L2 & ${ }^{\mathrm{a}} 0.39$ & $62 \pm 2$ & $-47 \pm 6$ & $-11 \pm 2$ & ${ }^{\mathrm{a}} 0.040$ & $70 \pm 1$ & $-36 \pm 3$ & $-8 \pm 1$ \\
\hline M2a-I & - & - & - & - & 0.046 & $63 \pm 2$ & $-60 \pm 6$ & $-9 \pm 1$ \\
\hline L3 & 0.40 & $57 \pm 2$ & $-62 \pm 7$ & $-11 \pm 2$ & 0.055 & $64 \pm 1$ & $-52 \pm 3$ & $-12 \pm 2$ \\
\hline M3 $\alpha-I$ & & & & & 0.067 & $62 \pm 1$ & $-59 \pm 3$ & $-11 \pm 1$ \\
\hline L4 & 0.25 & $63 \pm 1$ & $-47 \pm 3$ & $-8.3 \pm 0.1$ & 0.030 & $66 \pm 3$ & $-50 \pm 8$ & $-8 \pm 1$ \\
\hline M4 $\alpha-I$ & - & - & - & - & 0.038 & $64 \pm 1$ & $-62 \pm 4$ & $-7 \pm 1$ \\
\hline
\end{tabular}

${ }^{a}$ The different values from reference ${ }^{4 \mathrm{~b}}$ are due to a purification of the commercial $\mathbf{L 2}$ ligand done in this work.

The interpretation of the values of the activation parameters summarized in Table 1, is not straightforward in several ways. To start with, the values cannot be assigned to a simple kinetic step, as the determined rate constants are composites of an equilibrium constant for the formation of intermediates Ano-I or MAno-I and the first-order rate constant for the subsequent C-H bond activation (Scheme 1 and equations 1 and 2). Therefore, the thermal and the pressure activation parameters correspond to this product, and include the values of $\Delta H^{\circ}, \Delta S^{\circ}$, and $\Delta V^{\circ}$ for the formation equilibrium constants $\left(K_{1}\right.$ and $\left.K_{3}\right)$. Even more, only the values corresponding to the palladation from $\mathbf{M n} \boldsymbol{\alpha}$-I correspond to a proper single reaction pathway. For all the other processes studied, the reactivity corresponds to that of a mixture of the $\alpha$ and the putative $\beta$ isomer of An-I and Mn-I complexes (see the next section and Scheme 2). This is evident from the values of $\Delta H_{2}^{*}$ and $\Delta S_{2}^{*}$ collected in Table 1 for the dipalladation of the Ln derivatives, that correspond to the average of the reaction occurring on the $\alpha$ and $\beta$ isomers of Mn-I.

Interestingly, comparison of the data observed for the second palladation processes indicates that the values expected for the reactions occurring on the $\alpha$ unit of the Mn $\boldsymbol{\beta}$-I compounds should have larger activation enthalpies and less negative activation entropies, in order to attain the average data obtained as the second palladation of $\mathbf{L n}$. It seems clear that the metalation of the $\beta$-monometalated complexes, MAnß-I, by the palladium attached to $\mathrm{N}_{\alpha}$, has an earlier transition state with lower ordering but with higher enthalpy 
demands that has to be related to the presence of the donor $-\mathrm{NMe}_{2}$ on the meta position of the activating $\mathrm{C}-\mathrm{H}$ bond. This conclusion is further supported by the Wiberg bond orders of the $\mathrm{Pd}-\mathrm{C}$ and $\mathrm{C}-\mathrm{H}$ bonds in the transition states of MAn-I $\rightarrow$ Dn-I transformations (Table S13 and Figure S34 in SI_2). The Pd-C bond orders in MAnß-I $\rightarrow$ Dn-I transition states are lower than in the MAn $\boldsymbol{\alpha}-\mathbf{I} \rightarrow$ Dn-I counterparts, and the opposite relation holds for the $\mathrm{C}-\mathrm{H}$ bond orders (see also the last paragraph in this section).

Even with these difficulties in their final interpretation, plus the fact that the DMF-assisted process involves the exit of a positively charged $\{\mathrm{HDMF}\}^{+}$unit, the values of the activation parameters depicted in Table 1 are within the range of those determined for other base-assisted $\mathrm{C}-\mathrm{H}$ bond activations. ${ }^{3 \mathrm{a}-3 \mathrm{c}, 4 \mathrm{~d}}$ The negative values of $\Delta S^{\ddagger}$ and $\Delta V^{\ddagger}$ for both palladation steps agree with the presence of a highly ordered transition state in the rate determining step, which is supported by computational studies of the cyclopalladation mechanism. ${ }^{3 \mathrm{a},-3 \mathrm{c}, 4 \mathrm{a}, \mathrm{b}, \mathrm{d}}$ In this respect, the values determined for $\Delta S^{\ddagger}$ lay even lower than the lower-end of the available data for reactions having $\mathrm{AcO}^{-}$or $\mathrm{AcOH}$ as coordinating base-assisting ligands. ${ }^{3 a}$ This observation is in line with the fact that the less coordinating $\left(\mathrm{AcO}^{-}<\mathrm{AcOH}<\mathrm{DMF}\right)$ assisting base produces a lower degree of ordering on going to the transition state, that is occurs at a later position of the reaction coordinate.
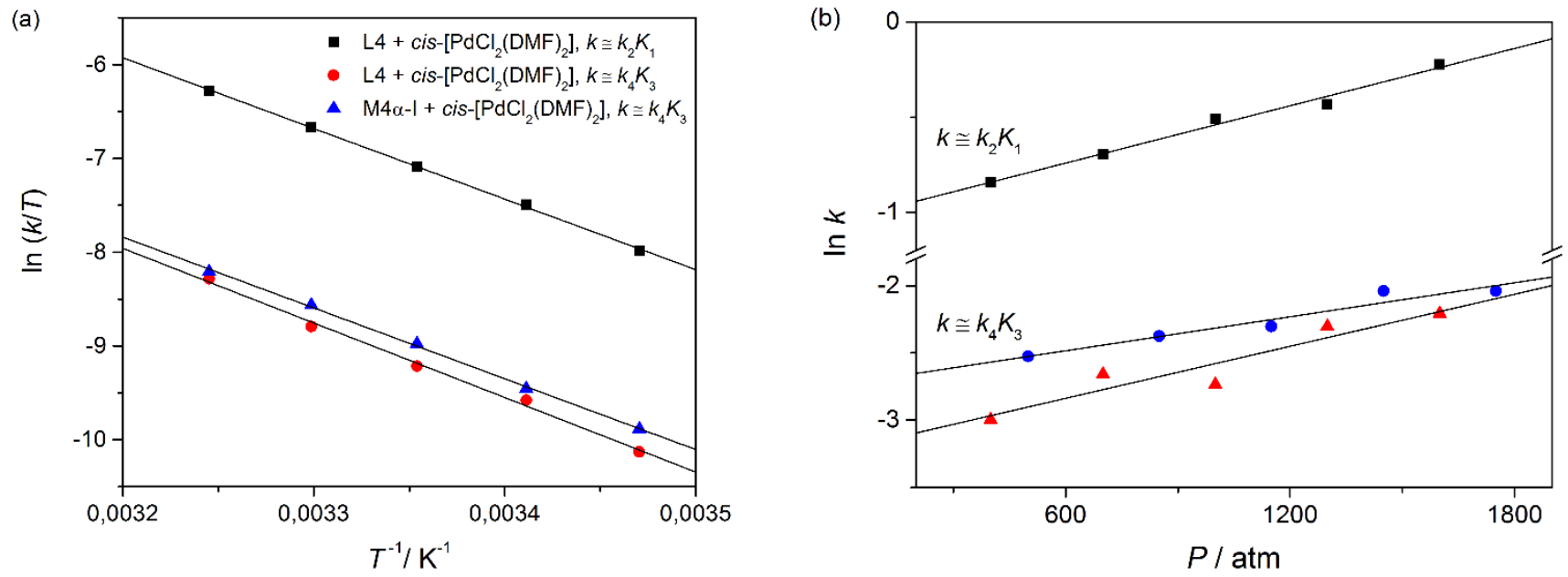

Figure 5. a) Eyring plots for the reaction sequence $\mathbf{L} \mathbf{4}+$ cis- $\left[\mathrm{PdCl}_{2}(\mathrm{DMF})_{2}\right] \rightarrow \mathbf{M} \mathbf{4} \boldsymbol{\alpha}-\mathbf{I}+$ cis- $\left[\mathrm{PdCl}_{2}(\mathrm{DMF})_{2}\right] \rightarrow \mathbf{D 4}-\mathbf{I}\left(k_{2} K_{1}\right.$ and $\left.k_{4} K_{3}\right)$, and the reaction $\mathbf{M 4} \boldsymbol{\alpha}-\mathbf{I}+$ cis-[ $\left.\mathrm{PdCl}_{2}(\mathrm{DMF})_{2}\right] \rightarrow \mathbf{D} 4-\mathbf{I}\left(k_{4} K_{3}\right)$. b) $\ln k$ versus $P$ plot for the reaction sequence $\mathbf{L} \mathbf{1}+$ cis-[PdCl$\left.{ }_{2}(\mathrm{DMF})_{2}\right] \rightarrow \mathbf{M 1} \boldsymbol{\alpha}-\mathbf{I}$ $+c i s-\left[\mathrm{PdCl}_{2}(\mathrm{DMF})_{2}\right] \rightarrow \mathbf{D} 1-\mathbf{I}\left(k_{2} K_{1}\right.$ and $k_{4} K_{3}$, red triangle $)$ and the reaction $\mathbf{M 1} \boldsymbol{\alpha}-\mathbf{I}+c i s-\left[\mathrm{PdCl}_{2}(\mathrm{DMF})_{2}\right] \rightarrow \mathbf{D 1}-\mathbf{I}\left(k_{4} K_{3}\right.$, blue circles $)$.

While all these findings fit well into the concerted metallation and deprotonation (CMD) mechanism proposed earlier, ${ }^{3 \mathrm{~b}, \mathrm{c}, 4 \mathrm{~d}}$ some recent results ${ }^{2 c, 16 a}$ indicate that this mechanism in fact comprises two subclasses distinguished by the site selectivity preferences. Those with nucleophilic affinity, towards more acidic $\mathrm{C}-\mathrm{H}$ bonds, are termed standard CMD, ${ }^{16}$ while those with electrophilic character are denoted as electrophilic CMD (eCMD). A clear identifying characteristics of this diversity is the Wiberg bond orders of the $\mathrm{Pd}-\mathrm{C}$ and $\mathrm{C}-\mathrm{H}$ bonds directly involved in the $\mathrm{C}-\mathrm{H}$ activation. ${ }^{2 \mathrm{c}, 16 \mathrm{a}} \mathrm{A}$ sum of these two Wiberg bond orders in the transition state geometry was established as a representative quantity. A critical value of 0.8 distinguishes the transition states of the standard CMD mechanism (with sum $<0.8$ ), from those in the $e$ CMD class (sum >0.8). In the present study, from the calculated transition state geometries $^{4 \mathrm{~b}}$ for all the ligands, for both cyclopalladation steps, and $\alpha, \beta$-paths, the sum of the two Wiberg indices are well above 0.8 (0.90-0.93, for all but MA5-I $\rightarrow$ D5 which has slightly outlying value of 0.85 , Table S13 and Figure 34 in SI-2), thus indicating an $e \mathrm{CMD}$ mechanism. The electrophilic nature of the present mechanism, as proven by the preference for $\mathrm{C}-\mathrm{H}$ bonds at the more electron-rich aromatic rings, also agrees with the meta-properties of the $e$ CMD mechanism.

NMR time-resolved monitoring. Since the coordination intermediates cannot be detected by UV-Vis spectroscopy, time-resolved ${ }^{1} \mathrm{H}$ NMR monitoring of the reactions of $\mathbf{L n}$ and $\mathbf{M n \alpha - I}$ with cis-[ $\left.\mathrm{PdCl}_{2}(\mathrm{DMF})_{2}\right]$ was conducted (Figures S13-S24). The procedure enabled the obtention of the concentration profiles of the species indicated in Scheme 2 (Figures S25-S33) and provided a detailed insight into the reaction dynamics.

Scheme 2. Kinetic model for the dipalladation of the azobenzenes used with cis-[PdCl$\left(\mathrm{PMF}_{2}\right]$ precursor $(\mathrm{labeled}$ as $\{\mathrm{Pd}\})$.

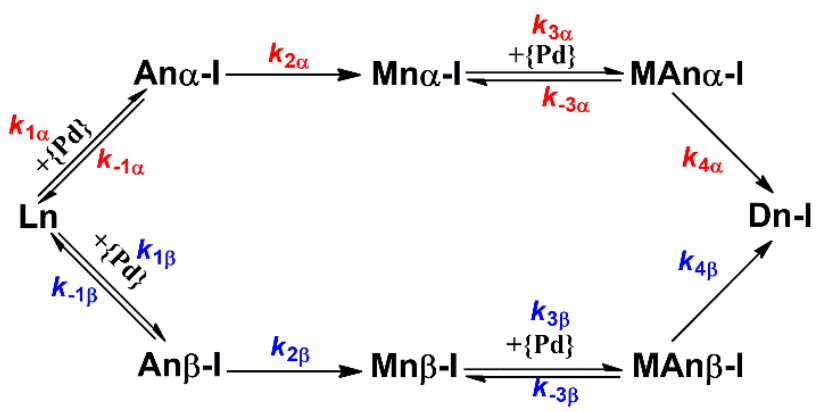


The kinetic model in Scheme 2 assumes two parallel cyclopalladation reaction pathways. These occur on the two possible isomers of the initial coordination compounds, that is An $\boldsymbol{\alpha}$-I and An $\boldsymbol{\beta}$-I. In both pathways, and for both mono- and di-cyclopalladation steps, the formation of each coordination complex is assumed to be a reversible process, while the subsequent proton transfer is considered as rate determining and irreversible, due to the removal of the aromatic proton. The ${ }^{1} \mathrm{H}$ NMR spectra of the reaction mixture at different times are consistent with the presence of the species indicated in Scheme 2. The signals of the Ano-I species were easily identified from the known spectra of the isolated $\alpha$-adducts, and those of An $\boldsymbol{\beta}$-I were recognized by their similarity with the $\alpha$ counterparts (Figures S13-S16).

Confirmation of the formation of both $\alpha$ - and $\beta$-isomers was obtained from the reaction of $\mathbf{L 5}$ with $c i s$ - $\left[\mathrm{PdCl}_{2}\left(\mathrm{DMF}_{2}\right]\right.$, where a single set of signals for A5-I was observed, given the equivalence of $\mathrm{N}_{\alpha}$ and $\mathrm{N}_{\beta}$ in L5 (Figures S17-S19). The signals of the Mn $\boldsymbol{\beta}$-I complexes were assigned based on similarities of their dynamics and NMR shifts with Mno-I species, and those of MAno, were ascertained from the simpler reactions initiated from Mno-I (Figures S21-24). The concentrations of MAn $\boldsymbol{\beta}$ were found, in all cases, too low to be detected or quantified reliably from the NMR spectra.

As indicated in the Experimental section, the NMR time-resolved speciation data was fed into the Dynafit software, ${ }^{17}$ with the kinetic model corresponding to Scheme 2. Even though M4 $\boldsymbol{\alpha}$-I and M5-I were effectively isolated as M4 $\alpha$-II and M5-II, the formation of the final Dn-I complexes always proceeded via Mno-I. Also, although azobenzenes are potentially able to bind to two Pd centers, these species were never detected despite the 10-fold excess of Pd precursor used in the experiments. In this respect, the computational results do not provide any reason for such an absence, ${ }^{4 \mathrm{~b}}$ hence their presence as transient species cannot be ruled out. However, if present in any significant amounts, the species should manifest themselves in the reaction kinetics, a fact that has not been observed.
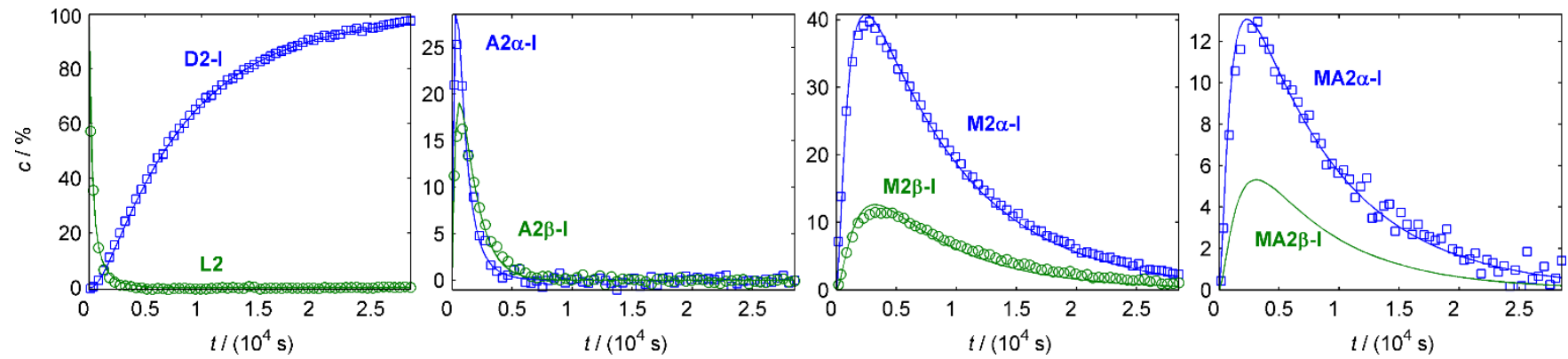

Figure 6. Experimental data and fitted concentration profiles for all the species present in the reaction $\mathbf{L} \mathbf{2}+$ cis- $\left[\mathrm{PdCl}_{2}(\mathrm{DMF})_{2}\right] \rightarrow \mathbf{A 2} \boldsymbol{\alpha}-\mathbf{I}+$

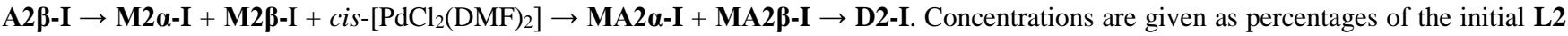
concentration. No reliable experimental data could be obtained for MA2 $\beta$-I.

Table 2. Dynafit fitted rate constants for the cyclopalladation of ligand L2 and its monopalladated derivative M2 $\alpha$-I.

\begin{tabular}{lcc}
\hline \multirow{2}{*}{ Rate constants } & \multicolumn{2}{c}{ Compounds } \\
\cline { 2 - 3 } & 0.43 & M2 $\alpha-\mathbf{I}$ \\
\hline$k_{1 \alpha}\left(\mathrm{M}^{-1} \mathrm{~s}^{-1}\right)$ & 0.00076 & - \\
$k_{-1 \alpha}\left(\mathrm{s}^{-1}\right)$ & 0.19 & - \\
\hline$k_{1 \beta}\left(\mathrm{M}^{-1} \mathrm{~s}^{-1}\right)$ & 0.00048 & \\
$k_{-1 \beta}\left(\mathrm{s}^{-1}\right)$ & 0.0019 & - \\
\hline$k_{2 \alpha}\left(\mathrm{s}^{-1}\right)$ & 0.00064 & - \\
\hline$k_{2 \beta}\left(\mathrm{s}^{-1}\right)$ & $*$ & 0.56 \\
\hline$k_{3 \alpha}\left(\mathrm{M}^{-1} \mathrm{~s}^{-1}\right)$ & $*$ & 0.0075 \\
\hline$k_{-3 \alpha}\left(\mathrm{s}^{-1}\right)$ & $*$ & - \\
\hline$k_{3 \beta}\left(\mathrm{M}^{-1} \mathrm{~s}^{-1}\right)$ & $*$ & 0.00054 \\
$k_{-3 \beta}\left(\mathrm{s}^{-1}\right)$ & 0.00053 & - \\
\hline$k_{4 \alpha}\left(\mathrm{s}^{-1}\right)$ & 0.00048 & \\
\hline$k_{4 \beta}\left(\mathrm{s}^{-1}\right)$ & & \\
\hline
\end{tabular}

*Due to significant uncertainty, these rate constants are omitted.

Kinetic modelling of NMR experiments was attempted for all reactions, but only the L2/M2 $\alpha$-I system produced reliable concentration profile fits for all the species in the reaction. Interestingly, this system is the one showing the largest differences between the data derived from the metalation of the $\mathbf{L n}$ and Mno-I compounds, see Table 1, indicating that it is in this reaction where the existence of a $\beta$-path is more significant. For the rest of the systems, NMR signal overlapping and poor signal-to-noise ratio did not allow the obtention of quantitative kinetic traces. Figures 7 and 8, and Table 2 collect the NMR speciation profiles, fitted kinetic traces and the 
derived second order rate constants for the reaction of full cyclopalladation of $\mathbf{L 2}$, and that of its monometalated $\mathbf{M} 2 \alpha-\mathbf{I}$ intermediate, with the cis-[ $\left[\mathrm{PdCl}_{2}(\mathrm{DMF})_{2}\right]$.

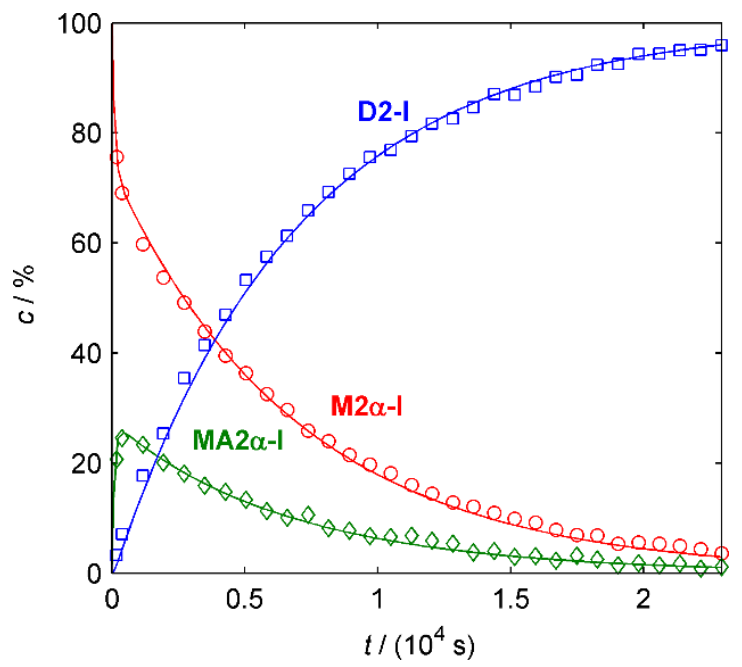

Figure 7. Experimental data and fitted concentration curves for the species present in the reaction $\mathbf{M} 2 \boldsymbol{\alpha}-\mathbf{I}+$ cis $-\left[\mathrm{PdCl}{ }_{2}(\mathrm{DMF})_{2}\right] \rightarrow \mathbf{M A 2} \boldsymbol{\alpha}-\mathbf{I}$ $\rightarrow$ D2-I. Concentrations are given as percentages of the initial M2 $\alpha-I$ concentration.

For the reactions from L1-L4 the concentration profiles indicated always higher concentrations of all $\alpha$-species, compared with their $\beta$-isomers (Figures S25-S28), as expected from the preparative results indicated before. The observed difference can be interpreted as a higher stability (or a faster formation) of the $\alpha$-isomers; in the case of the An $\alpha$-I and An $\boldsymbol{\beta}$-I complexes this fact is consistent with the relation between the equilibrium constants $\left(K_{1 \alpha}=k_{1 \alpha} / k_{-1 \alpha}\right)>\left(K_{1 \beta}=k_{1 \beta} / k_{-1 \beta}\right)$. Similarly, from the data collected in Table 2 we can conclude that the $\mathbf{M} 2 \alpha-I$ species are formed faster than the M2 $\beta$-I isomers, as expected for the cyclopalladation occurring preferentially on the ring bearing the electron-donating - $\mathrm{NMe}_{2}$ group (see previous compounds section). ${ }^{18}$

Remarkably, the reaction of intermediate M5-I to produce D5-I was only completed after one month, under NMR concentration conditions, which effectively indicates that mono- and dipalladation processes can be considered as two fully separate processes for this system (Figures S17-S18). For the rest of the systems, the dicyclopalladated products are formed immediately once the monopalladated intermediates are present in the reaction medium (Figures S13-S16). The reaction profiles indicated that the formation rates of mono- or dipalladated species increase in the order L5 (M5) $<$ L4 (M4) $<$ L2 (M2) $<$ L3 (M3) $<$ L1 (M1), which is consistent with the donor strengths of 4,4'-substituents on azobenzenes

A comparison of the results obtained from UV-Vis and NMR time-resolved experiments on the $\mathbf{L} \mathbf{2}$ and $\mathbf{M} \mathbf{2} \alpha-\mathbf{I}$ systems reveals that for the second metalation step of $\mathbf{L} \mathbf{2}$ system, the values obtained for the second order rate constants are in extraordinary agreement $\left(0.039 \mathrm{M}^{-1} \mathrm{~s}^{-1}\right.$ versus $\left.0.040 \mathrm{M}^{-1} \mathrm{~s}^{-1}\right)$, which reinforces the idea that the $\beta$ path is expected to be of minor importance due to a very low $K_{3}$ value. For the first metalation step, only the order of magnitude is in agreement $\left(0.39 \mathrm{M}^{-1} \mathrm{~s}^{-1}\right.$ versus $\left.1.0 \mathrm{M}^{-1} \mathrm{~s}^{-1}\right)$, a much more realistic result taking into account the large methodological differences used.

Even so, the difference for the latter can be associated very easily with the very high value of $k_{1 \alpha} / k_{\text {-1 } \alpha}$ obtained from the NMR measurements. This value ( $c a$. 700-800 $\mathrm{M}^{-1}$ ) should lead to the presence of an, unobserved, saturation behavior in the plots in Figures 3 and S7-S8. The difference can be associated to a very low, underestimated, value obtained for $k_{\text {-1a }}$ due to limitations of the NMR technique at very short times and low concentration of the A2 $\alpha$-I species (see Figure 6).

\section{CONCLUSIONS}

We have conducted a kinetico-mechanistic study of cyclopalladation reactions involving activation of azobenzene $\mathrm{C}-\mathrm{H}$ bonds by cis- $\left[\mathrm{PdCl}_{2}(\mathrm{DMF})_{2}\right]$ in DMF, both on the free ligands and on their already monopalladated derivatives. All reactions were monitored by time-resolved NMR and UV-Vis spectroscopies at different Pd-precursor concentrations, temperatures and pressures. The concentration profiles obtained by NMR monitoring enabled a direct insight into the reactivity and nature of the observed and putative intermediates, most of which have also been isolated and structurally characterized.

NMR results confirmed that the dipalladation of asymmetrically substituted azobenzenes is a multistep process involving two concurrent reaction paths. These involve an inverse sequential order for the $\mathrm{C}-\mathrm{H}$ bond activation at the two possible cyclopalladation sites of the azo-derivative. A kinetic model, with a minimum number of fitting parameters, has been found capable to explain the concentration-time profiles of the reaction species. Very satisfactory results were obtained for some of the systems studied, providing a precise view of the reaction dynamics in solution. From the kinetic parameters obtained, one of the reaction paths is found to be dominant, a result also featured by the known computational study of the full process. The successful application of the kinetic model also supports the hypothesis that bis-palladium coordination compounds do not participate in azobenzene $\mathrm{C}-\mathrm{H}$ bond activation at an appreciable extent.

Although less specific on the nature of the both reacting species and intermediates, UV-Vis monitoring has been successfully applied for the interpretation of the global kinetic model. Furthermore, the complete agreement of the data necessitates consideration of the two parallel paths resolved by NMR spectroscopy, despite one being dominant. The values of the thermal and pressure activation parameters provided additional support for the base assisted mechanism operating in these cyclopalladation reactions. These 
values are consistent with a highly ordered and compressed transition state in which the basic DMF ligand participates in the proton abstraction producing an anionic species that quickly exchanges one of the two remaining chloride ligands by a new DMF ligand from the solvent. In view of the recently established distinction between the CMD mechanisms, the process evidently belongs to the $e$ CMD class, as clearly indicated by the Pd-C and C-H Wiberg bond orders in the $\mathrm{C}-\mathrm{H}$ activation transition states.

The results obtained represent an important contribution with a remarkable synergy between diverse but complementary techniques. This complete image of the full process will allow the better design and preparation of new cyclopalladated complexes in the Pd-catalyzed reactions of substrates having multiple $\mathrm{C}-\mathrm{H}$ bonds available for functionalization.

\section{EXPERIMENTAL SECTION}

General Methods. All chemicals and solvents were of reagent grade and used without additional purifications (except the L2 ligand). NMR spectra of MeCN- $d_{3}$, DMF- $d_{7}$, and/or DMSO- $d_{6}$ solutions were recorded on Bruker AV-600, AV-400 and, AV-300 spectrometers at $25^{\circ} \mathrm{C}$. IR spectra were recorded on an AAB Bomem MB 102 spectrophotometer using the Nujol mull method (4000-200 cm-1), and on a Perkin-Elmer Spectrum Two spectrometer. CHN analyses were carried out with a Perkin-Elmer Series II 2400 CHNS/O analyzer. PXRD data were obtained by using Ni-filtered $\mathrm{Cu} K_{\alpha}$ radiation on a PANalytical Aeris X-ray diffractometer. Single crystals structures of $\mathbf{A} 1 \boldsymbol{\alpha}-\mathbf{I}, \mathbf{A} \mathbf{3} \boldsymbol{\alpha}-\mathbf{I}$ and $\mathbf{M 1} \boldsymbol{\alpha}-\mathbf{I}$, D1-I, were isolated from standing $\mathrm{MeCN}$ and DMF solutions, respectively, and were measured on an Oxford Diffraction Xcalibur Nova R (microfocus Cu tube) at $20{ }^{\circ} \mathrm{C}$.

Kinetic Measurements. The reactions of azobenzenes and their monopalladated compounds with $c i s$ - $\left[\mathrm{PdCl}_{2}(\mathrm{DMF})_{2}\right]$ precursor were monitored by time-resolved ${ }^{1} \mathrm{H}$ NMR spectroscopy in DMF- $d_{7}$ solutions on a Bruker AV-400 spectrometer at $25^{\circ} \mathrm{C}$. Solutions for the kinetic runs were prepared by addition of $50 \mu \mathrm{L}$ of a DMF- $d_{7}$ solution of the precursor $\left(6.04 \times 10^{-2} \mathrm{M}\right)$ to $500 \mu \mathrm{L}$ of a solution of the ligand, or the monopalladated compound, (ca. $5.5 \times 10^{-4} \mathrm{M}$ in DMF- $d_{7}$ ) in a NMR tube. After the addition of the $c i s-\left[\mathrm{PdCl}_{2}(\mathrm{DMF})_{2}\right]$ solution, spectra were acquired at diverse time intervals, depending on the reaction rate. The kinetic traces of the species showing well resolved signals and good signal-to-noise ratio were fit with the Dynafit software. ${ }^{17}$

The same reactions were also followed by UV-Vis time-resolved spectroscopy at variable palladium precursor concentrations, temperatures and pressures. The variable temperature kinetic experiments at atmospheric pressure were monitored in the full $350-780 \mathrm{~nm}$ range on a Cary $50 \mathrm{UV}-\mathrm{Vis}$ spectrophotometer equipped with a thermostatted multicell transport $\left( \pm 0.1^{\circ} \mathrm{C}\right)$ and under pseudo-first-order conditions (palladium in at least 20 -fold molar excess). The solutions were prepared by mixing the necessary volumes of a DMF solution of ligand, or monopalladated compound, with a DMF solution of cis-[ $\left.\mathrm{PdCl}_{2}(\mathrm{DMF})_{2}\right]$ in a $1 \mathrm{~cm} \mathrm{UV}-\mathrm{V}$ is cuvette, the final volume was achieved by adding DMF. For the reactions carried out at varying pressure, the same sample preparation procedure was followed. The previously described pillbox cell and pressurizing system were used, and the final treatment of data was the same as described before. ${ }^{4 \mathrm{~d}}$ For these measurements, and given the excellent linearity observed for the $k_{\mathrm{obs}}$ versus [Pd] plots (see Figures 3 and S6-S7), the values of the second order rate constants were derived from a single $k_{\text {obs }} /[\mathrm{Pd}]$ ratio at a given palladium precursor concentration (as done for some other very well-behaved systems). ${ }^{19}$ The calculation of the observed rate constants from the absorbance versus time monitoring of reactions was carried out using the SPECFIT software. ${ }^{20}$ All post-run fittings were carried out using standard software. In general, the errors for the rate constants derived were within the $5 \%$ margin.

Synthesis of Compounds. The coordination complexes (trans-A1 $\alpha-\mathbf{I}$, trans-A2 $\alpha-\mathbf{I}$, trans-A3 $\alpha-\mathbf{I}$ and A5-III) and monopalladated derivatives

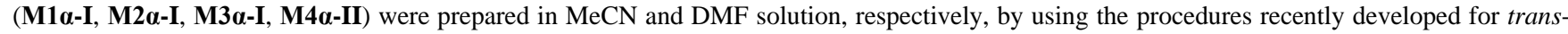
A2 $\alpha$-I and $\mathbf{M 2} \alpha$-I. ${ }^{8}$ Reaction of $\mathbf{L} 4$ with $\mathrm{PdCl}_{2}$ in $\mathrm{MeCN}$ afforded the mixture of $\mathbf{A 4} \boldsymbol{\alpha}$-I and $\mathbf{A 4 \alpha} \boldsymbol{\alpha}$-II structures. Monopalladated complex M5-II was prepared in methanol according to the previously reported procedure. ${ }^{8 \mathrm{~b}}$

cis- $\left[\mathrm{PdCl}_{2}(\mathrm{DMF})_{2}\right]$ was prepared by exposing solid $\mathrm{PdCl}_{2}(60 \mathrm{mg}, 0.34 \mathrm{mmol})$ to DMF vapor at room temperature for $72 \mathrm{~h}$. Yield: quantitative. Found: C 21.90, H 4.66, N 8.88; Calcd. for $\mathrm{C}_{6} \mathrm{H}_{14} \mathrm{Cl}_{2} \mathrm{~N}_{2} \mathrm{O}_{2} \mathrm{Pd}$ : C 22.28, H 4.36, N 8.66 (method 1). $80 \mathrm{mg}(0.45 \mathrm{mmol})$ of $\mathrm{PdCl}_{2}$ was dissolved in 10 $\mathrm{mL}$ of DMF and filtered off. The resulting solution was evaporated at $50{ }^{\circ} \mathrm{C}$ for 15 minutes and cooled at- $25^{\circ} \mathrm{C}$ for two hours. The product was filtered off and dried under vacuum. Yield: $36 \%$. (method 2).

trans- $\left[\mathrm{PdCl}_{2}\left(\mathrm{C}_{6} \mathrm{H}_{5} \mathrm{~N}=\mathrm{NC}_{6} \mathrm{H}_{4} \mathrm{NMe}_{2}\right) \mathrm{MeCN}\right] \cdot \mathrm{MeCN}$, trans-A1a-I structure. A mixture of $\mathrm{PdCl}_{2}(70 \mathrm{mg}, 0.39 \mathrm{mmol})$ and $\mathbf{L 1}(89 \mathrm{mg}, 0.39 \mathrm{mmol})$ was stirred in $\mathrm{MeCN}$ for $30 \mathrm{~h}$. The product was filtered off and dried under vacuum. Yield: 76\%. Found: C 44.52, H 4.61, N 14.18; Calc. for $\mathrm{C}_{18} \mathrm{H}_{21} \mathrm{Cl}_{2} \mathrm{~N}_{5} \mathrm{Pd}$ : C 44.60, H 4.37, N 14.45. ${ }^{1} \mathrm{H} \mathrm{NMR}\left(\mathrm{MeCN}_{-} d_{3}, \delta / \mathrm{ppm}, J / \mathrm{Hz}\right): 9.59 \mathrm{~d}\left(\mathrm{H}-2,6,{ }^{3} J(\mathrm{HH})=9.4\right), 7.09 \mathrm{~d}\left(\mathrm{H}-3,5,{ }^{3} J(\mathrm{HH})=9.5\right), 8.58 \mathrm{~d}(\mathrm{H}-$ $\left.8,12,{ }^{3} J(\mathrm{HH})=7.5\right), 7.50 \mathrm{t}\left(\mathrm{H}-9,11,{ }^{3} J(\mathrm{HH})=7.9\right), 7.50 \mathrm{t}\left(\mathrm{H}-10,{ }^{3} J(\mathrm{HH})=7.2\right), 3.27 \mathrm{~s}\left(\mathrm{NMe}_{2}\right)$.

trans-[ $\mathrm{PdCl}_{2}\left(\mathrm{IC}_{6} \mathrm{H}_{4} \mathrm{~N}=\mathrm{NC}_{6} \mathrm{H}_{4} \mathrm{NMe}_{2}\right) \mathrm{MeCN}$ ], trans-A3 $\alpha-\mathbf{I}$ structure. A mixture of $\mathrm{PdCl}_{2}(70 \mathrm{mg}, 0.39 \mathrm{mmol})$ and $\mathbf{L 3}(138 \mathrm{mg}, 0.39 \mathrm{mmol})$ was stirred in $\mathrm{MeCN}$ for $30 \mathrm{~h}$. The product was filtered off and dried under vacuum. Yield: 88\%. Found: C 33.96, H 2.88, N 10.19; Calc. for $\mathrm{C}_{16} \mathrm{H}_{17} \mathrm{Cl}_{2} \mathrm{IN} 4 \mathrm{Pd}$ : C 33.74, H 3.01, N 9.84. ${ }^{1} \mathrm{H}$ NMR $\left(\mathrm{MeCN}-d_{3}, \delta / \mathrm{ppm}, J / \mathrm{Hz}\right): 9.60 \mathrm{~d}\left(\mathrm{H}-2,6,{ }^{3} J(\mathrm{HH})=9.3\right), 7.09 \mathrm{~d}\left(\mathrm{H}-3,5,{ }^{3} J(\mathrm{HH})=9.5\right), 8.37 \mathrm{~d}(\mathrm{H}-$ $\left.8,12,{ }^{3} J(\mathrm{HH})=8.5\right), 7.90 \mathrm{~d}\left(\mathrm{H}-9,11,{ }^{3} J(\mathrm{HH})=8.5\right), 3.28 \mathrm{~s}\left(\mathrm{NMe}_{2}\right)$.

$\left[\mathrm{PdCl}_{2}\left(\mathrm{C}_{6} \mathrm{H}_{4} \mathrm{~N}=\mathrm{NC}_{6} \mathrm{H}_{5}\right)_{2}\right]$, A5-III. A mixture of $\mathrm{PdCl}_{2}(50 \mathrm{mg}, 0.28 \mathrm{mmol})$ and $\mathbf{~ L 5}(102 \mathrm{mg}, 0.56 \mathrm{mmol})$ was stirred in MeCN for $30 \mathrm{~h}$. The product was filtered off, washed with diethyl ether and dried under vacuum. Yield: $48 \%$. Found: $\mathrm{C} 52.81, \mathrm{H} 3.97, \mathrm{~N} 10.13 ; \mathrm{Calc}$ for $\mathrm{C}_{24} \mathrm{H}_{20} \mathrm{Cl}_{2} \mathrm{~N}_{4} \mathrm{Pd}$ : $\mathrm{C} 53.21$, H 3.72, N 10.34. ${ }^{1} \mathrm{H}$ NMR (DMF- $\left.d 7, \delta / \mathrm{ppm}, J / \mathrm{Hz}\right): 8.43 \mathrm{~d}\left(\mathrm{H}-2,6,{ }^{3} J(\mathrm{HH})=7.5\right), 7.93-7.99 \mathrm{~m}(\mathrm{H}-3,4,5), 8.34 \mathrm{~d}\left(\mathrm{H}-8,12,{ }^{3} J(\mathrm{HH})=8.6\right), 7.67 \mathrm{t}(\mathrm{H}-$ $\left.9,11,{ }^{3} J(\mathrm{HH})=7.7\right), 7.78 \mathrm{t}\left(\mathrm{H}-10,{ }^{3} J(\mathrm{HH})=7.4\right)$.

$\left[\mathrm{PdCl}\left(\mathrm{C}_{6} \mathrm{H}_{5} \mathrm{~N}=\mathrm{NC}_{6} \mathrm{H}_{3} \mathrm{NMe}_{2}\right)(\mathrm{DMF})\right], \mathbf{M 1} \alpha-\mathrm{I}$. Complex trans-A1 $\alpha-\mathbf{I}(100 \mathrm{mg}, 0.21 \mathrm{mmol})$ was stirred in DMF at room temperature for ten days. The product was filtered off and dried under vacuum. Yield $48 \%$. Found: $\mathrm{C} 46.86, \mathrm{H} 4.95, \mathrm{~N} 12.55$; Calc. for $\mathrm{C}_{17} \mathrm{H}_{21} \mathrm{ClN} \mathrm{N}_{4} \mathrm{OPd}$ : C 46.48, $\mathrm{H} 4.82, \mathrm{~N}$ 12.76. ${ }^{1} \mathrm{H}$ NMR (DMSO- $\left.d 6, \delta / \mathrm{ppm}, J / \mathrm{Hz}\right): 7.02 \mathrm{~s}$, br $(\mathrm{H}-3), 6.58 \mathrm{~d}, \mathrm{br}\left(\mathrm{H}-5,{ }^{3} J(\mathrm{HH})=8.4\right), 7.62 \mathrm{~d}\left(\mathrm{H}-6,{ }^{3} J(\mathrm{HH})=7.6\right), 7.62 \mathrm{~d}\left(\mathrm{H}-8,12,{ }^{3} J(\mathrm{HH})=7.6\right)$, $7.35 \mathrm{t}\left(\mathrm{H}-10,{ }^{3} J(\mathrm{HH})=7.1\right), 7.42 \mathrm{t}\left(\mathrm{H}-9,11,{ }^{3} J(\mathrm{HH})=7.4\right), 3.13 \mathrm{~s}\left(\mathrm{NMe}_{2}\right)$.

$\left[\mathrm{PdCl}\left(\mathrm{C}_{6} \mathrm{H}_{4} \mathrm{IN}=\mathrm{NC}_{6} \mathrm{H}_{3} \mathrm{NMe}_{2}\right)(\mathrm{DMF})\right], \mathbf{M 3 \alpha}$-I. Complex trans-A3a-I $(100 \mathrm{mg}, 0.18 \mathrm{mmol})$ was stirred in DMF at room temperature for seven days. The product was filtered off and dried under vacuum. Yield $67 \%$. Found: $\mathrm{C} \mathrm{35.82,} \mathrm{H} \mathrm{3.94,} \mathrm{N} \mathrm{10.25;} \mathrm{Calc.} \mathrm{for} \mathrm{C}_{17} \mathrm{H}_{20} \mathrm{ClIN}_{4} \mathrm{OPd}$ : $\mathrm{C} 36.13$, $\mathrm{H}$ 3.57, N 9.91. ${ }^{1} \mathrm{H}$ NMR (DMSO- $\left.d_{6}, \delta / \mathrm{ppm}, J / \mathrm{Hz}\right): 7.00 \mathrm{~s}$, br $(\mathrm{H}-3), 6.59 \mathrm{~d}$, br $\left(\mathrm{H}-5,{ }^{3} J(\mathrm{HH})=8.6\right), 7.62 \mathrm{~d}$, br $\left(\mathrm{H}-6,{ }^{3} J(\mathrm{HH})=8.5\right), 7.45 \mathrm{~d}(\mathrm{H}-8,12$, $\left.{ }^{3} J(\mathrm{HH})=8.4\right), 7.76 \mathrm{~d}\left(\mathrm{H}-9,11,{ }^{3} J(\mathrm{HH})=8.6\right), 3.14 \mathrm{~s}\left(\mathrm{NMe}_{2}\right)$.

$\left[\mathrm{Pd}(\mu-\mathrm{Cl})\left(\mathrm{C}_{6} \mathrm{H}_{4} \mathrm{NO}_{2} \mathrm{~N}=\mathrm{NC}_{6} \mathrm{H}_{3} \mathrm{NMe}_{2}\right)\right]_{2}, \mathbf{M} 4 \boldsymbol{\alpha}$-II. The mixture of complexes trans-A4 $\boldsymbol{\alpha}-\mathbf{I}$ and $\mathbf{A 4} \boldsymbol{\alpha}-\mathrm{II}(100 \mathrm{mg})$ was stirred in DMF at room temperature for seven days. The product was filtered off and dried under vacuum. Yield $51 \%$. Found: C 40.52, H 3.44, N 13.28; Calc. for $\mathrm{C}_{28} \mathrm{H}_{26} \mathrm{Cl}_{2} \mathrm{~N}_{8} \mathrm{O}_{4} \mathrm{Pd}_{2}: \mathrm{C} 40.90, \mathrm{H} 3.19, \mathrm{~N} 13.63 .{ }^{1} \mathrm{H}$ NMR (DMSO- $\left.d_{6}, \delta / \mathrm{ppm}, J / \mathrm{Hz}\right): 7.09 \mathrm{~s}$, br $(\mathrm{H}-3), 6.69 \mathrm{~d}$, br $\left(\mathrm{H}-5,{ }^{3} J(\mathrm{HH})=8.3\right), 7.69 \mathrm{~d}, \mathrm{br}(\mathrm{H}-6$, $\left.{ }^{3} J(\mathrm{HH})=8.5\right), 7.90 \mathrm{~d}\left(\mathrm{H}-8,12,{ }^{3} J(\mathrm{HH})=8.4\right), 8.26 \mathrm{~d}\left(\mathrm{H}-9,11,{ }^{3} J(\mathrm{HH})=8.7\right), 3.20 \mathrm{~s}\left(\mathrm{NMe}_{2}\right)$.

$\left[\{\mathrm{PdCl}(\mathrm{DMF})\}_{2}\left(\mu-\mathrm{C}_{6} \mathrm{H}_{4} \mathrm{~N}=\mathrm{NC}_{6} \mathrm{H}_{3} \mathrm{NMe}_{2}\right)\right]$, D1-I. A mixture of M1 $\alpha-\mathbf{I}(100 \mathrm{mg}, 0.23 \mathrm{mmol})$ and trans-[ $\left.\mathrm{PdCl}_{2}(\mathrm{MeCN})_{2}\right](118 \mathrm{mg}, 0.46 \mathrm{mmol})$ was stirred in DMF for seven days at room temperature. The product was filtered off and dried under vacuum. Yield 75\%. Found: $\mathrm{C} 36.44, \mathrm{H} 4.42, \mathrm{~N}$ 10.38; Calcd. for $\mathrm{C}_{20} \mathrm{H}_{27} \mathrm{Cl}_{2} \mathrm{~N}_{5} \mathrm{O}_{2} \mathrm{Pd}_{2}$ : C 36.77, $\mathrm{H} 4.17, \mathrm{~N} 10.72 .{ }^{1} \mathrm{H}$ NMR (DMSO- $\left.d_{6}, \delta / \mathrm{ppm}, J / \mathrm{Hz}\right): 7.23 \mathrm{~s}(\mathrm{H}-3), 6.63 \mathrm{~d}\left(\mathrm{H}-5,{ }^{3} J(\mathrm{HH})=9.6\right), 8.51$ $\mathrm{d}\left(\mathrm{H}-6,{ }^{3} J(\mathrm{HH})=9.6\right), 7.68 \mathrm{~d}\left(\mathrm{H}-9,{ }^{3} J(\mathrm{HH})=7.7\right), 6.88 \mathrm{t}\left(\mathrm{H}-10,{ }^{3} J(\mathrm{HH})=7.6\right), 7.05 \mathrm{t}\left(\mathrm{H}-11,{ }^{3} J(\mathrm{HH})=7.6\right), 8.29 \mathrm{~d}\left(\mathrm{H}-12,{ }^{3} J(\mathrm{HH})=8.2\right), 3.19 \mathrm{~s}(\mathrm{NMe})$. 
[\{PdCl(DMF) $\left.\}_{2}\left(\mu-\mathrm{C}_{6} \mathrm{H}_{3} \mathrm{ClN}=\mathrm{NC}_{6} \mathrm{H}_{3} \mathrm{NMe}_{2}\right)\right]$, D2-I. A mixture of M2 $\boldsymbol{\alpha}-\mathbf{I}(100 \mathrm{mg}, 0.21 \mathrm{mmol})$ and trans-[PdCl $2\left(\mathrm{MeCN}_{2}\right](109 \mathrm{mg}, 0.42 \mathrm{mmol})$ was stirred in DMF for seven days at room temperature. The product was filtered off and dried under vacuum. Yield 83\%. Found: C 34.55, $\mathrm{H} 3.36$, $\mathrm{N}$ 9.95; Calcd. for $\mathrm{C}_{20} \mathrm{H}_{26} \mathrm{Cl}_{3} \mathrm{~N}_{5} \mathrm{O}_{2} \mathrm{Pd}_{2}$ : C 34.93, $\mathrm{H} 3.81, \mathrm{~N} 10.18 .{ }^{1} \mathrm{H} \mathrm{NMR}$ (DMSO- $\left.d 6, \delta / \mathrm{ppm}, J / \mathrm{Hz}\right): 7.23 \mathrm{~s}(\mathrm{H}-3), 6.64 \mathrm{~d}\left(\mathrm{H}-5,{ }^{3} J(\mathrm{HH})=9.4 \mathrm{~Hz}\right)$, $8.49 \mathrm{~d}\left(\mathrm{H}-6,{ }^{3} J(\mathrm{HH})=9.3 \mathrm{~Hz}\right), 7.63 \mathrm{~s}(\mathrm{H}-9), 7.13 \mathrm{~d}\left(\mathrm{H}-11,{ }^{3} J(\mathrm{HH})=8.7 \mathrm{~Hz}\right), 8.28 \mathrm{~d}\left(\mathrm{H}-12,{ }^{3} J(\mathrm{HH})=8.7 \mathrm{~Hz}\right), 3.20 \mathrm{~s}\left(\mathrm{NMe}_{2}\right)$.

$\left[\left\{\mathrm{PdCl}(\mathrm{DMF}\}_{2}\left(\mu-\mathrm{C}_{6} \mathrm{H}_{3} \mathrm{IN}=\mathrm{NC}_{6} \mathrm{H}_{3} \mathrm{NMe}_{2}\right)\right]\right.$, D3-I. A mixture of M3a-I $(100 \mathrm{mg}, 0.18 \mathrm{mmol})$ and trans-[PdCl$\left(\mathrm{PeCN}_{2}\right](91 \mathrm{mg}, 0.35 \mathrm{mmol})$ was stirred in DMF for seven days at room temperature. The product was filtered off and dried under vacuum. Yield 73\%. Found: $\mathrm{C} 31.18, \mathrm{H} 3.01, \mathrm{~N}$ 9.30; Calcd. for $\mathrm{C}_{20} \mathrm{H}_{26} \mathrm{Cl}_{2} \mathrm{IN}_{5} \mathrm{O}_{2} \mathrm{Pd}_{2}$ : C 30.83, H 3.36, $\mathrm{N}$ 8.99. ${ }^{1} \mathrm{H}$ NMR (DMSO- $\left.d_{6}, \delta / \mathrm{ppm}, J / \mathrm{Hz}\right) 7.22 \mathrm{~s}(\mathrm{H}-3), 6.65 \mathrm{~d}\left(\mathrm{H}-5,{ }^{3} J(\mathrm{HH})=9.8\right), 8.49 \mathrm{~d}$ $\left(\mathrm{H}-6,{ }^{3} J(\mathrm{HH})=9.4\right), 7.99 \mathrm{~s}(\mathrm{H}-9), 7.44 \mathrm{~d}\left(\mathrm{H}-11,{ }^{3} J(\mathrm{HH})=8.4\right), 8.04 \mathrm{~d}\left(\mathrm{H}-12,{ }^{3} J(\mathrm{HH})=8.3\right), 3.19 \mathrm{~s}\left(\mathrm{NMe}_{2}\right)$.

[\{PdCl(DMF) $\left.\}_{2}\left(\mu-\mathrm{C}_{6} \mathrm{H}_{3} \mathrm{NO}_{2} \mathrm{~N}=\mathrm{NC}_{6} \mathrm{H}_{3} \mathrm{NMe}_{2}\right)\right]$, D4-I. A mixture of $\mathbf{M} 4 \boldsymbol{\alpha}-\mathbf{I I}(100 \mathrm{mg}, 0.12 \mathrm{mmol})$ and trans-[PdCl $2\left(\mathrm{MeCN}_{2}\right](123 \mathrm{mg}, 0.48 \mathrm{mmol})$ was stirred in DMF for seven days at room temperature. The product was filtered off and dried under vacuum. Yield 75\%. Found: C 34.77, $\mathrm{H} \mathrm{3.41,}$ $\mathrm{N}$ 11.88. Calcd. for $\mathrm{C}_{20} \mathrm{H}_{26} \mathrm{Cl}_{2} \mathrm{~N}_{6} \mathrm{O}_{4} \mathrm{Pd}_{2}$ : C $34.40, \mathrm{H} 3.75, \mathrm{~N} 12.04 .{ }^{1} \mathrm{H} \mathrm{NMR}$ (DMSO- $\left.d_{6}, \delta / \mathrm{ppm}, J / \mathrm{Hz}\right): 7.30 \mathrm{~s}(\mathrm{H}-3), 6.80 \mathrm{~d}\left(\mathrm{H}-5,{ }^{3} J(\mathrm{HH})=9.1 \mathrm{~Hz}\right)$, $8.35 \mathrm{~d}\left(\mathrm{H}-6,{ }^{3} J(\mathrm{HH})=9.0 \mathrm{~Hz}\right), 8.43 \mathrm{~s}(\mathrm{H}-9), 7.94 \mathrm{~d}\left(\mathrm{H}-11,{ }^{3} J(\mathrm{HH})=9.2 \mathrm{~Hz}\right), 8.59 \mathrm{~d}\left(\mathrm{H}-12,{ }^{3} J(\mathrm{HH})=9.2 \mathrm{~Hz}\right), 3.28 \mathrm{~s}\left(\mathrm{NMe}_{2}\right)$.

$\left[\{\mathrm{PdCl}(\mathrm{DMF})\}_{2}\left(\mu-\mathrm{C}_{6} \mathrm{H}_{4} \mathrm{~N}=\mathrm{NC}_{6} \mathrm{H}_{4}\right)\right]$, D5-I. A mixture of M5-II $(80 \mathrm{mg}, 0.12 \mathrm{mmol})$ and trans-[ $\mathrm{PdCl}_{2}\left(\mathrm{MeCN}_{2}\right](128 \mathrm{mg}, 0.49 \mathrm{mmol}) \mathrm{was}$ stirred in DMF for 14 days at room temperature. The product was filtered off and dried under vacuum. Yield 73\%. Found: C 35.07, H 3.26, N 9.39.; Calcd. for $\mathrm{C}_{18} \mathrm{H}_{22} \mathrm{Cl}_{2} \mathrm{~N}_{4} \mathrm{O}_{2} \mathrm{Pd}_{2}: \mathrm{C} 35.43, \mathrm{H} 3.63, \mathrm{~N} 9.18 .{ }^{1} \mathrm{H}$ NMR (DMSO- $\left.d_{6}, \delta / \mathrm{ppm}, J / \mathrm{Hz}\right): 7.87 \mathrm{~d}\left(\mathrm{H}-3,9,{ }^{3} J(\mathrm{HH})=7.2 \mathrm{~Hz}\right), 7.18 \mathrm{t}\left(\mathrm{H}-4,10,{ }^{3} J(\mathrm{HH})=7.2\right.$ $\mathrm{Hz}), 7.14 \mathrm{t}\left(\mathrm{H}-5,11,{ }^{3} J(\mathrm{HH})=7.23 \mathrm{~Hz}\right), 8.75 \mathrm{~d}$, br $\left(\mathrm{H}-6,12,{ }^{3} J(\mathrm{HH})=6.9 \mathrm{~Hz}\right)$.

\section{ASSOCIATED CONTENT}

\section{Supporting Information}

The Supporting Information is available free of charge on the ACS Publications website at DOI:

Additional spectra, PXRD, kinetic data and computational details including DFT geometries and their energies are given. (PDF) Accession Codes

CCDC 1994905, 1995310-1995313 contain the supplementary crystallographic data for this paper. These data can be obtained free of charge via www.ccdc.cam.ac.uk/data_request/cif, or by emailing data_request@ccdc.cam.ac.uk, or by contacting The Cambridge Crystallographic Data Center, 12 Union Road, Cambridge CB2 1EZ, UK; fax: +44 1223336033.

\section{AUTHOR INFORMATION}

\section{Corresponding Author}

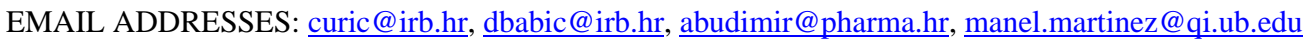

Notes

\$ These authors contributed equally. The authors declare no competing financial interests.

\section{ACKNOWLEDGMENT}

This work has been supported by Croatian Science Foundation under project number IP-2019-04-9951 and by the Spanish Ministerio de Ciencia e Innovación under project PID2019-107006GB-C21. Computations were done on the Isabella cluster at SRCE, Zagreb.

\section{REFERENCES}

1) (a) Whitehurst, W. G.; Gaunt, M. J. Synthesis and Reactivity of Stable Alkyl-Pd(IV) Complexes Relevant to Monodentate N-Directed C(sp ${ }^{3}$ )-H Functionalization Processes. J. Am. Soc. 2020, 142, 14169-14177. https://doi.org/10.1021/jacs.0c04732. (b) Dickmu, D. C.; Smoliakova, I. P. Cyclopalladated complexes containing an (sp(3))C-Pd bond. Coord. Chem. Rev. 2020, 409, 21320. https://doi.org/10.1016/j.ccr.2020.213203. (c) Tylkowski, B.; Trojanowska, A.; Marturano, V.; Nowak, M.; Marciniak, L.; Giamberini, M.; Ambrogi, V.; Cerruti, P. Power of light-Functional complexes based on azobenzene molecules. Coord. Chem. Rev. 2017, 351, 205-217. https://doi.org/10.1016/i.ccr.2017.05.009. (d) Kapdi, A. R.; Fairlamb, I.J. S. Anti-cancer palladium complexes: a focus on $\mathrm{PdX}_{2} \mathrm{~L}_{2}$, palladacycles and related complexes. Chem. Soc. Rev. 2014, 43, 4751-4777. https://doi.org//10.1039/c4cs00063c. (e) Dehand, J.; Pffefer,M. Cyclometallated Compounds. Coord. Chem. Rev. 1976, 18, 327-352. http://dx.doi.org/10.1016/S0010-8545(00)80431-2. (f) Omae, I. Intramolecular five-membered ring compounds and their applications. Coord. Chem. Rev. 2004, 248, 995-1023. https://doi.org/10.1016/j.ccr.2004.05.011. (g) Albrecht, M. Cyclometalation Using d-Block Transition Metals: Fundamental Aspects and Recent Trends. Chem. Rev. 2010, 110, 576-623. https://doi.org/10.1021/cr900279a. (h) Dupont, J.; Consorti, C. S.; Spencer, J. The Potential of Palladacycles: More than Just Precatalysts. Chem. Rev. 2005, 105, 2527-2572. https://doi.org/10.1021/cr030681r. (i) Palladacycles: Synthesis, Characterization and Applications (Eds. Dupont, J.; Pfeffer, M.), Wiley-VCH, Weinheim, 2008. (j) Ghedini, M.; Aiello, I.; Crispini, A.; Golemme, A.; La Deda, M.; Pucci, D. Azobenzenes and Heteroaromatic Nitrogen Cyclopalladated Complexes for Advanced Applications. Coord. Chem. Rev. 2006, 290, 1373-1390. https://doi.org/10.1016/j.ccr.2005.12.011. (k) Wakatsuki, Y.; Yamazaki, H.; Grutsch, P. A.; Santhanam, M.; Kutal, C. Study of Intramolecular Sensitization and Other Excited-State Pathways in Orthometalated Azobenzene Complexes of Palladium(II). $J$. Am. Chem. Soc. 1985, 107, 8153-8159. https://doi.org/10.1021/om9609574.

(2) (a) Chen, Y.-Q.; Singh, S.; Wu, Y. Wang, Z.; Hao, W.; Verma, P.; Qiao, J. X.; Sunoj, R. B. Yu, J.-Q. Pd-Catalyzed $\gamma$-C(sp $\left.{ }^{3}\right)-H$ Fluorination of Free Amines. J. Am. Chem. Soc. 2020, 142, 9966-9974. https://dx.doi.org/10.1021/jacs.9b13537. (b) Park, H. S.; Fan, Z.;Zhu, R.-Y.; Yu, J.-Q. Distal $\gamma-\mathrm{C}\left(\mathrm{sp}^{3}\right)-\mathrm{H}$ Olefination of Ketone Derivatives and Free Carboxylic Acids Angew. Chem. Int, Ed. 2020, 132, $12953-12959$.

https://doi.org/10.1002/anie.202003271. (c) Wang, L.; Carrow, B. P. Oligothiophene Synthesis by a General C-H Activation Mechanism: Electrophilic Concerted Metalation-Deprotonation (eCMD). ACS Catal. 2019, 9, 6821-6836. https://doi.org/10.1021/acscatal.9b01195. (d) Qian, S.; Li, Z.Q.; Li, M.; Wisniewski, S. R.; Qiao, J. X.; Richter, J. M.; Ewing, W. R.; Eastgate, M. D.; Chen, J. S.; Yu, J.-Q. Ligand-Enabled Pd(II)-Catalyzed $\mathrm{C}\left(\mathrm{sp}^{3}\right)-\mathrm{H}$ Lactonization Using Molecular Oxygen as Oxidant. Org. Lett. 2020, 22, 3960-3963.

https://dx.doi.org/10.1021/acs.orglett.0c01243. (e) Malapit, C. A.; Ichiishi, N.; Sanford, M. S. Pd-Catalyzed Decarbonylative Cross-Couplings of Aroyl Chlorides. Org. Lett. 2017, 19, 4142-4145.

https://dx.doi.org/10.1021/acs.orglett.7b02024. (f) Topczewski, J. J.; Cabrera, P. J.; Saper, N. I.; Sanford, M. S. Palladium-Catalyzed Transannular C-H Functionalization of Alicyclic Amines. Nature, 2016, 531, 220-224. https://dx.doi.org/10.1038/nature16957. (g) Ryabov, A. D. Cyclopalladated 
Complexes in Organic Synthesis. Synthesis 1985, 233-252. https://doi.org/10.1055/s-1985-31169 3. (h) McNally, A.; Haffemayer, B.; Collins, B. S. L.; Gaunt, M. J. Palladium-Catalysed C-H Activation of Aliphatic Amines to Give Strained Nitrogen Heterocycles. Nature, 2014, 510, 129-133. https://doi.org/10.1038/nature13389. (i) Yamaguchi, J.; Yamaguchi, A. D.; Itami, K. C-H Bond Functionalization: Emerging Synthetic Tools for Natural Products and Pharmaceuticals. Angew. Chem. Int. Ed. 2012, 51, 8960-9009.

https://doi.org/10.1002/anie.201201666. (j) Ackermann, L. Carboxylate-Assisted Transition-Metal-Catalyzed C-H Bond Functionalizations: Mechanism and Scope. Chem. Rev. 2011, 111, 1315-1345. https://doi.org/10.1021/cr100412j. (k) Godula, K.; Sames, D. C-H Bond Functionalization in Complex Organic Synthesis. Science, 2006, 312, 67-62. https://doi.org/10.1126/science.1114731. (1) Lyons, T; W. Sanford, M. S. PalladiumCatalyzed Ligand-Directed C-H Functionalization Reactions. Chem, Rev. 2010, 110, 1147-1169.

https://doi.org/10.1021/cr900184e.

(3) (a) Granell, J.; Martinez M. Kinetico-mechanistic studies of cyclometalating C-H bond activation reactions on Pd(II) and Rh(II) centres: The importance of non-innocent acidic solvents in the process. Dalton Trans. 2012, 41, 11243-11258.

https://doi.org/10.1039/c2dt30866e. (b) Laga, E.; Garcia-Montero, A.; Sayago, F. J.; Soler, T.; Moncho, C.; Cativiela, C.; Martinez, M.; Urriolabeitia, E. P. Cyclopalladation and Reactivity of Amino Esters through C-H Bond Activation: Experimental, Kinetic, and Density Functional Theory Mechanistic Studies. Chem. Eur. J. 2013, 19, 17398-17412. https://doi.org/10.1002/chem.201302693. (c) Roiban, G.D.; Serrano, E.; Soler, T.; Aullón, G.; Grosu, I.; Cativiela, C.; Martinez, M.; Urriolabeitia, E. P. Regioselective Orthopalladation of (Z)-2-Aryl-4-Arylidene-5(4H)-Oxazolones: Scope, Kinetico-Mechanistic, and Density Functional Theory Studies of the $\mathrm{C}-\mathrm{H}$ Bond Activation. Inorg. Chem. 2011, 50, 8132-8143. https://doi.org/10.1021/ic200564d. (d) Ryabov, A. D.; Sakodinskaya, I. K.; Yatsimirski, A. Kinetics and Mechanism of Ortho-Palladation of RingSubstituted N,N-dimethylbenzylAmines K. J. Chem. Soc. Dalton Trans. 1985, 2629-2638.

https://doi.org/10.1039/DT9850002629. (e) Yagyu, T.; Aizawa, S.; Funahashi, S. Mechanistic Studies on Cyclopalladation of the Solvated Palladium(II) Complexes with $N$-Benzyl Triamine Ligands in Various Solvents. Crystal Structures of $\left[\mathrm{Pd}\left(\mathrm{Sol}_{)}\left(\mathrm{Bn}_{2} \mathrm{Medptn}\right)\right]\left(\mathrm{BF}_{4}\right)_{2}(\mathrm{Sol}=\mathrm{Acetonitrile}\right.$

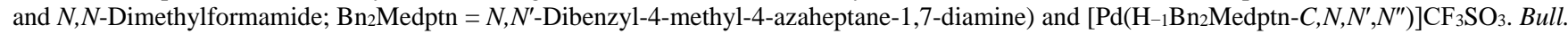
Chem. Soc. Jpn. 1998, 71, 619-629. https://doi.org/10.1246/bcsj.71.619. (f) Yagyu, T.; Iwatsuki, S.; Aizawa, S.; Funahashi, S. Electronic Effect of Substituents on Cyclopalladation of the Solvated Palladium(II) Complexes with $N$-Benzyl Triamine $\left[\mathrm{Pd}_{(\mathrm{Sol})}\right)\left\{\left(4-\mathrm{XC}_{6} \mathrm{H}_{4} \mathrm{CH}_{2}\right) \mathrm{NH}_{(}\left(\mathrm{CH}_{2}\right)_{3} \mathrm{NR}-\right.$ $\left.\left.\left(\mathrm{CH}_{2}\right)_{3} \mathrm{NH}_{2}\right\}\right]^{2+}\left(\mathrm{Sol}=\right.$ Solvent; $\mathrm{R}=\mathrm{Ph}, \mathrm{H}$, and $\mathrm{Me} ; \mathrm{X}=\mathrm{H}, \mathrm{Et}, \mathrm{Me}, \mathrm{MeO}, \mathrm{Cl}$, and $\left.\mathrm{NO}_{2}\right)$. Bull. Chem. Soc. Jpn. 1998, 71, 1857-1862. https://doi.org/10.1246/bcsj.71.1857. (g) Gomez, M.; Granell, J.; Martinez, M. Mechanisms of Cyclopalladation Reactions in Acetic Acid: Not So Simple One-Pot Processes. Eur. J. Inorg. Chem. 2000, 217-224. https://doi.org/10.1002/(SICI)1099-0682(200001)2000:1<217::AIDEJIC217>3.0.CO;2-Q.

(4) (a) Babić, D.; Ćurić, M.; Smith, D. M. Computational Study of the Cyclopalladation Mechanism of Azobenzene with $\mathrm{PdCl}_{2}$ in $N, N$-Dimethylformamide. J. Organomet. Chem. 2011, 696, 661-669. https://doi.org/10.1016/j.jorganchem.2010.09.038. (b) Juribašić, M.; Budimir, A.; Kazazić, S.; Ćurić, M. Dicyclopalladated Complexes of Asymmetrically Substituted Azobenzenes: Synthesis, Kinetics and Mechanisms. Inorg. Chem. 2013, $52,12749-12757$.

https://pubs.acs.org/doi/10.1021/ic402017v. (c) Aullón, G.; Chat, R.; Favier, I.; Font-Bardia, M.; Gomez, M.; Granell, J.; Martinez, M.; Solans, X. Cyclometallation of amino-imines on palladium complexes. The effect of the solvent on the experimental and calculated mechanism. Dalton Trans, 2009, 8292-8300. https://doi.org/10.1039/B905134A.

(d) Font, H.; Font-Bardia, M.; Gómez, K.; González, G.; Granell, J.; Macho, I.; Martínez, M. A kinetico-mechanistic study on the C-H bond activation of primary benzylamines; cooperative and solid-state cyclopalladation on dimeric complexes. Dalton Trans. 2014, $13525-135236$.

https://doi.org/10.1039/C4DT01463D. (e) Gomez, M.; Granell, J.; Martinez, M. Variable-temperature and-pressure kinetics and mechanism of the cyclopalladation reaction of imines in aprotic solvent. Organometallics, 1997, 16, 2593-2546.

https://doi.org/10.1021/om961099e. (f) Favier, I.; Gomez, M.; Granell, J.; Martinez., M.; Font-Bardia, M.; Solans, X.; Font-Bardia, M. Kineticomechanistic studies of $\mathrm{C}-\mathrm{H}$ bond activation on new $\mathrm{Pd}$ complexes containing $N, N^{\prime}$-chelating ligands. Dalton. Trans. 2005, 123-132. https://doi.org/10.1039/B415613G.

(5) (a) Grimster, N. P.; Gauntlett, C.; Godfrey, C. R. A.; Gaunt, M. J. Palladium-Catalyzed Intermolecular Alkenylation of Indoles by SolventControlled Regioselective C-H Functionalization. Angew. Chem., Int. Ed. 2005, 44, 3125-3129. https://doi.org/10.1002/anie.200500468. (b) Ulery, H. E. A Novel Preparation of Amidinium Arsenesulfonates. J. Org. Chem. 1965, 30, 2464-2465. https://doi.org/10.1021/jo01018a510. (c) Mei, T. S.; Wang, X.; Yu, J.-Q. Pd(II)-Catalyzed Amination of C-H Bonds Using Single-Electron or Two-electron Oxidants. J. Am. Chem. Soc. 2009, 131, 10806-10807. https://doi.org/10.1021/ja904709b. (d) Chiong, H. A.; Pham, Q. N.; Daugulis, O. Two Methods for Direct ortho-Arylation of Benzoic Acids. J. Am. Chem. Soc. 2007, 129, 9879-9884.

https://doi.org/10.1021/ja071845e. (e) Zaitsev, V. G.; Daugulis, O. Highly Regioselective Arylation of sp ${ }^{3}$ C-H Bonds Catalyzed by Palladium Acetate. J. Am. Chem. Soc. 2005, 127, 13154-13155.

https://doi.org/10.1021/ja054549f.

(6) (a) Mottillo, C.; Lu, Y.; Pham, M.-H.; Cliffe, M. J.; Do, T.-O.; Friščić, T. Mineral Neogenesis as an Inspiration for Mild, Solvent-Free Synthesis of Bulk Microporous Metal-Organic Frameworks from Metal (Zn, Co) Oxides. Green Chem. 2013, 15, 2121.

https://doi.org/10.1039/C3GC40520F. (b) Cliffe, M. J.; Mottillo, C.; Bučar, D.-K.; Friščić, T. Accelerated Aging: a Low Energy, Solvent-Free Alternative to Solvothermal and Mechanochemical Synthesis of Metal-Organic Materials Chem. Sci. 2012, 3, 2495.

https://doi.org/10.1039/C2SC20344H (c) Braga, D.; Giaffreda, S. L.; Grepioni, F.; Chierotti, M. R.; Gobetto, R.; Palladino, G.; Polito, M. Solvent Effect in a "Solvent Free" Reaction. CrystEngComm. 2007, 9, 879.

https://doi.org/10.1039/B711983F (d) Monas, A.; Užarević, K.; Halasz, I.; Juribašić Kulcsár, M.; Ćurić, M. Vapour-Induced Solid-State C-H bond Activation for the Clean Synthesis of an Organopalladium Biothiol Sensor. Chem. Commun. 2016, 52, 12960-12963. https://doi.org/10.1039/C6CC06062E.

(7) (a) Donati, M.; Morelli, D.; Conti, F.; Ugo, R. Complessi dimetilammidici di alcuni metalli del grupo del platino, Chim. Ind. 1968, 50, 231235. (b) Wayland, B. B.; Schramm, R. F. Cationic and Neutral Chloride Complexes of Palladium(II) with the Nonaqueous Solvent Donors Acetonitrile, Dimethyl Sulfoxide, and a Series of Amides. Mixed Sulfur and Oxygen Coordination Sites in a Dimethyl Sulfoxide Complex, Inorg. Chem. 1969, 8, 971-976. https://doi.org/10.1021/ic50074a050. (c) Gioria, J. M.; Susz, B. P. Etude des composés d'addition des acides de Lewis - XXXV. Note sur les composés d'addition entre amides et, respectivement, $\mathrm{PdCl}_{2}$ et $\mathrm{PtCl}_{2}$, Helv. Chim. Acta 1971, 54, 2251-2256. https://doi.org/10.1002/hlca.19710540762.

(8) Bjelopetrović, A.; Lukin, S.; Halasz, I.; Užarević, K.; Đilović, I.; Barišić, D.; Budimir, A.; Juribašić Kulcsár, Ćurić, M. Mechanism of Mechanochemical C-H Bond Activation in an Azobenzene Substrate by Pd(II) Catalysts. Chem. Eur. J. 2018, 24, 10672. https://doi.org/10.1002/chem.201802403.

(9) Juribašić Kulcsár, M.; Halasz, I.; Babić, D.; Cinčić, D.; Plavec, J.; Ćurić, M. Aging and Ball-Milling as Low-Energy and Environmentally Friendly Methods for the Synthesis of Pd(II) Photosensitizers. Organometallics, 2014, 33, 1227-1234. https://doi.org/10.1021/om500008v. 
(10) Khare, G. P.; Little, R. G.; Veal, J. T.; Doedens, R. J. Crystal and Molecular Structure of Dichlorobis(azobenzene)palladium(II), a Possible Intermediate in the Ortho Palladation of Azobenzene. Inorg. Chem. 1975, 14, 2475-2479. https://doi.org/10.1021/ic50152a037.

(11) Ćurić, M.; Tušek-Božić, Lj.; Vikić-Topić, D.; Scarcia, V.; Furlani, A.; Balzarini, J.; DeClercq, E. Palladium(II) Complexes of Dialkyl $\alpha$ Anilinobenzylphosphonates. Synthesis, Characterization, and Cytostatic activity. J. Inorg. Biochem. 1996, 63, 125-142.

https://doi.org/10.1016/0162-0134(95)00199-9.

(12) Roy, S.; Hartenbach, I.; Sarkar, B. Structures, Redox and Spectroscopic Properties of Pd ${ }^{\mathrm{II}}$ and Pt $\mathrm{Pt}^{\mathrm{II}}$ Complexes Containing an Azo Functionality. Eur. J. Inorg. Chem. 2009, 2553-2558. https://doi.org/10.1002/ejic.200900007.

(13) (a) Babić, D.; Ćurić, M.; Molčanov, K.; Ilc, G.; Plavec, J. Synthesis and Characterization of Dicyclopalladated Complexes of Azobenzene Derivatives by Experimental and Computational Methods. Inorg. Chem. 2008, 47, 10446-10454. https://doi.org/10.1021/ic8010234. (b) Ćurić, M.; Babić, D.; Višnjevac, A; Molčanov, K. Simple Route to the Doubly ortho-Palladated Azobenzenes: Building Blocks for Organometallic Polymers and Metallomesogens. Inorg. Chem. 2005, 44, 5975. https://doi.org/10.1021/ic050747w.

(14) Ryabov, A. D. Mechanisms of intramolecular activation of carbon-hydrogen bonds in transition-metal complexes. Chem. Rev. 1990, 90, 403424. https://doi.org/10.1021/cr00100a004.

(15) (a) Espenson, J. H. Chemical Kinetics and Reaction Mechanisms, McGraw-Hill, New York, 1981. (b) Tobe, M. L.; Burgess, J. Inorganic Reaction Mechanisms, Longman, New York, 1999.

(16) (a) Carrow, B. P.; Sampson, J.; Wang, L. Base-Assisted C-H Bond Cleavage in Cross-Coupling: Recent Insights into Mechanism, Speciation, and Cooperativity. Isr. J. Chem. 2019, 59, 230-258.

https://doi.org/10.1002/ijch.201900095. (b) Alharis, R. A.; McMullin, C. L. Davies, D. L.; Singh, K.; Macgregor, S. A. The Importance of Kinetic and Thermodynamic Control when Assessing Mechanisms of Carboxylate-Assisted C-H Activation. J. Am. Chem. Soc. 2019, 141, 8896-8906. https://doi.org/10.1021/jacs.9b02073. (c) Yang, Y.-F.; Yu, J.-Q.; Houk, K. N. Experimental-Computational Synergy for Selective Pd(II)-Catalyzed C-H Activations of Aryl and Alkyl Groups. Acc. Chem. Res. 2017, 50, 2853-2860.

https://doi.org/10.1021/acs.accounts.7b00440. (d) Yang, Y.-F.; Cheng, G.-J.; Liu, P.; Leow, D.; Sun, T.-Y.; Chen, P.; Zhang, P.; Yu, J.-Q.; Wu, Y.D.; Houk, K, N. Palladium-Catalyzed Meta-Selective C-H Bond Activation with a Nitrile-Containing Template: Computational Study on Mechanism and Origins of Selectivity. J. Am. Chem. Soc. 2014, 136, 344-355. https://doi.org/10.1021/ja410485g.(e) Jiang, J.; Yu, J.-Q.; Morokuma, KMechanism and Stereoselectivity of Directed $\mathrm{C}\left(\mathrm{sp}^{3}\right)-\mathrm{H}$ Activation and Arylation Catalyzed by Pd(II) with Pyridine Ligand and Trifluoroacetate: A Computational Study. ACS Catal. 2015, 5, 3648-3661. https://doi.org/10.1021/cs501626n. (f) Davies, D. L.; Macgregor, S. A.; McMullin, S. A. Computational Studies of Carboxylate-Assisted $\mathrm{C}-\mathrm{H}$ Activation and Functionalization at Group 8-10 Transition Metal Centers. Chem. Rev. 2017, 117, 8649-8709.

https://doi.org/10.1021/acs.chemrev.6b00839. (g) Wang, P.; Verma, P.; Xia, G.; Shi, J.; Qiao, J. X.; Tao, S.; Cheng, P. T. W.; Poss, M. A.; Farmer, M. E.; Yeung, K.-S.; Yu, J.-Q. Ligand-accelerated non-directed C-H functionalization of arenes. Nature, 2017, 551, 489-493. https://doi.org/ 10.1038/nature24632. (h) Engle. K. M.; Wang, D.-H.; Yu, J.-Q. Ligand-Accelerated C-H Activation Reactions: Evidence for a Switch of Mechanism. J. Am. Chem. Soc. 2010, 132, 14137-14151.

https://doi.org/10.1021/ja105044s.

(17) (a) Kuzmič, P. Program DYNAFIT for the analysis of enzyme kinetic data: Application to HIV proteinase. Anal. Biochem. 1996, 237, 269273. https://doi.org/10.1006/abio.1996.0238. (b) Kuzmič, P. DYNAFIT - a software package for enzymology. Methods Enzymol. 2009, 467, 247280. https://doi.org/10.1016/S0076-6879(09)67010-5.

(18) Wakatsuki, Y.; Yamazaki, H.; Grutsch, P. A.; Santhanam, M.; Kutal, C. Study of intramolecular sensitization and other excited-state pathways in orthometalated azobenzene complexes of palladium(II). J. Am. Chem. Soc. 1985, 107, 8153-8159. https://doi.org/10.1021/om9609574.

(19) Bernhard, P. V.; Gonzálvez, M.V.; Martinez, M. Kinetico-mechanistic Study on the Oxidation of Biologically Active Iron(II) Bis(thiosemicarbazone) Complexes by Air. Importance of $\mathrm{NH} \cdots \mathrm{O}_{2}$ Interactions as Established by Activation Volumes. Inorg. Chem. 2017, 56, 1428-14290. https://pubs.acs.org/doi/abs/10.1021/acs.inorgchem.7b02381.

(20) Binstead, R. A.; Züberbuhler A. D.; Jung, B. SPECFIT32. [3.0.34], Spectrum Software Associates, 2005.

\section{Table of Contents Synopsis}

A kinetico-mechanistic study of the $\mathrm{C}-\mathrm{H}$ bond activation in azobenzenes and their monopalladated derivatives with cis$\left[\mathrm{PdCl}_{2}(\mathrm{DMF})_{2}\right]$ in DMF has been conducted by time-resolved NMR and UV-Vis spectroscopies at variable concentration, temperature and pressure. NMR spectra enabled detailed insight into the nature and reactivity of intermediates and confirmed that the dipalladation of 4,4'-functionalized azobenzenes is a multistep process involving two reaction pathways.

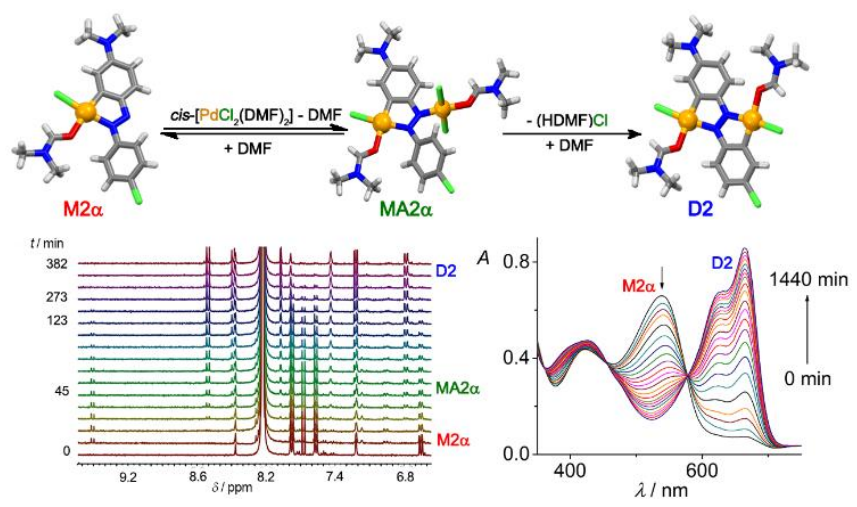

